\title{
Condition-dependence, pleiotropy and the handicap principle of sexual selection in melanin-based colouration
}

\author{
Alexandre Roulin* \\ Department of Ecology and Evolution, University of Lausanne, Building Biophore, 1015 Lausanne, Switzerland
}

\begin{abstract}
The signalling function of melanin-based colouration is debated. Sexual selection theory states that ornaments should be costly to produce, maintain, wear or display to signal quality honestly to potential mates or competitors. An increasing number of studies supports the hypothesis that the degree of melanism covaries with aspects of body condition (e.g. body mass or immunity), which has contributed to change the initial perception that melanin-based colour ornaments entail no costs. Indeed, the expression of many (but not all) melanin-based colour traits is weakly sensitive to the environment but strongly heritable suggesting that these colour traits are relatively cheap to produce and maintain, thus raising the question of how such colour traits could signal quality honestly. Here I review the production, maintenance and wearing/displaying costs that can generate a correlation between melanin-based colouration and body condition, and consider other evolutionary mechanisms that can also lead to covariation between colour and body condition. Because genes controlling melanic traits can affect numerous phenotypic traits, pleiotropy could also explain a linkage between body condition and colouration. Pleiotropy may result in differently coloured individuals signalling different aspects of quality that are maintained by frequency-dependent selection or local adaptation. Colouration may therefore not signal absolute quality to potential mates or competitors (e.g. dark males may not achieve a higher fitness than pale males); otherwise genetic variation would be rapidly depleted by directional selection. As a consequence, selection on heritable melanin-based colouration may not always be directional, but mate choice may be conditional to environmental conditions (i.e. context-dependent sexual selection). Despite the interest of evolutionary biologists in the adaptive value of melanin-based colouration, its actual role in sexual selection is still poorly understood.
\end{abstract}

Key words: colour polymorphism, honest signalling, melanin, pleiotropy, sexual selection, social interactions.

\section{CONTENTS}

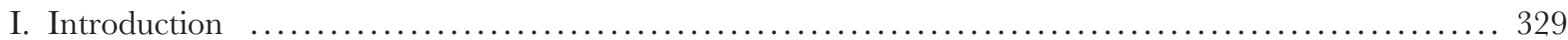

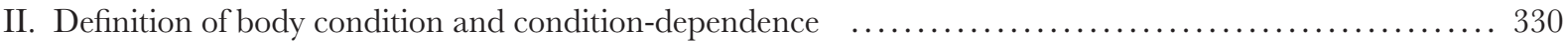

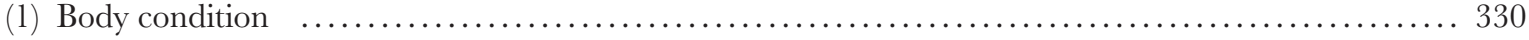

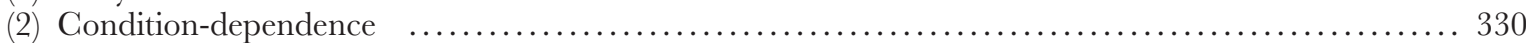

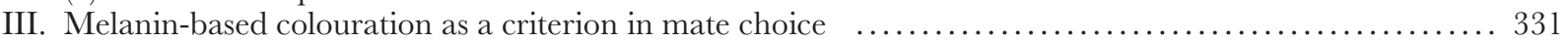

IV. Proximate mechanisms of the covariation between melanin-based colouration and body condition $\quad \ldots . . .332$

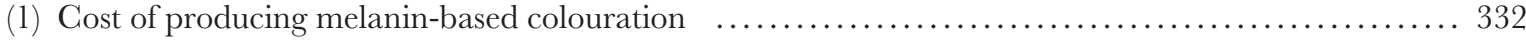

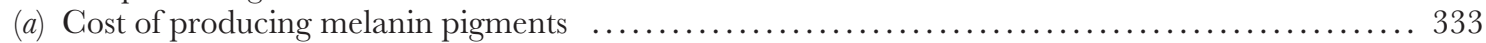

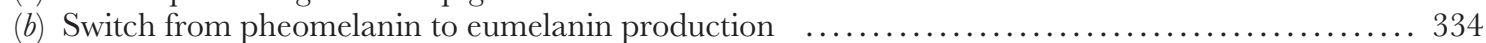

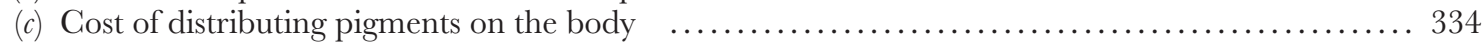

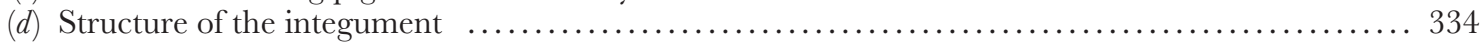

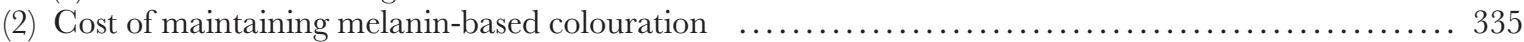

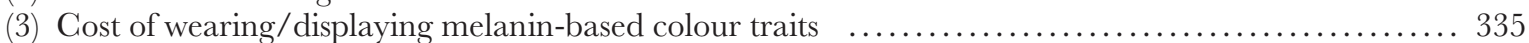

(a) Social control of the honesty of melanin-based colouration as a signal of body condition $\ldots . \ldots . .335$

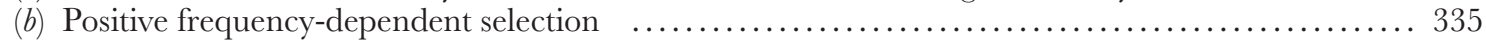

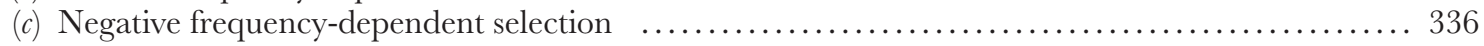

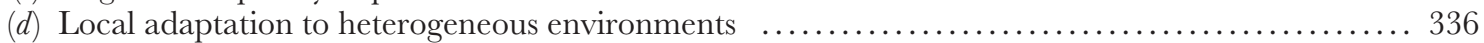

\footnotetext{
* Address for correspondence (Tel: +41 7968608 64; E-mail: Alexandre.Roulin@unil.ch).
} 
(4) The role of pleiotropy in generating covariation between colouration and body condition $\ldots \ldots \ldots 336$

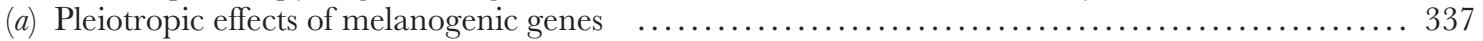

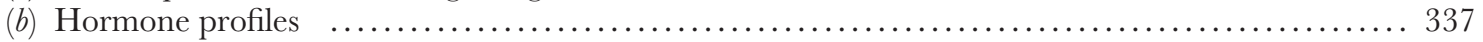

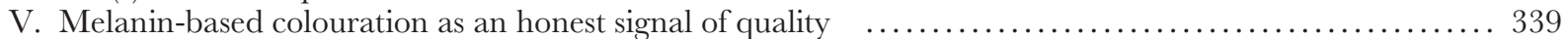

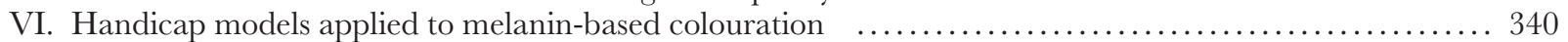

(1) Conditional handicaps or costs of producing melanin-based colouration $\ldots \ldots \ldots \ldots \ldots \ldots \ldots \ldots$

(2) Revealing handicaps or costs of producing melanin-based colouration $\ldots \ldots \ldots \ldots \ldots \ldots \ldots \ldots \ldots$

(3) Pure epistatic handicap or costs of wearing a melanin-based colour trait $\ldots \ldots \ldots \ldots \ldots \ldots \ldots \ldots$

(4) Pleiotropic handicaps or pleiotropic effects of melanogenic genes $\ldots \ldots \ldots \ldots \ldots \ldots \ldots \ldots \ldots \ldots \ldots \ldots$

VII. Evolutionary stability of genetic variation in melanin-based colouration $\ldots \ldots \ldots \ldots \ldots \ldots \ldots \ldots \ldots \ldots \ldots \ldots$

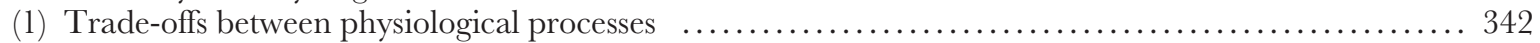

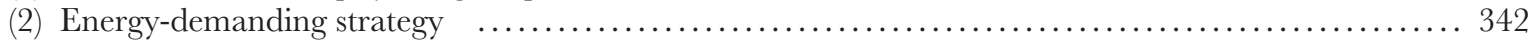

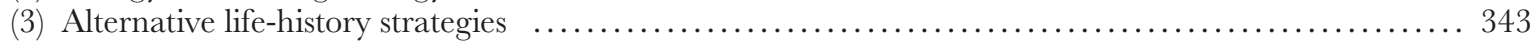

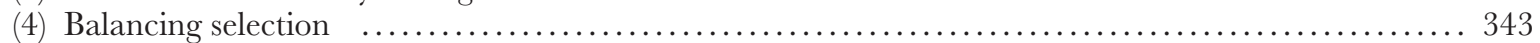

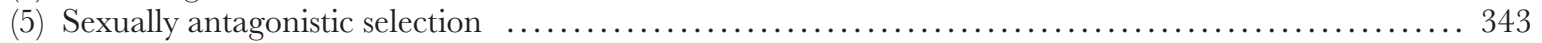

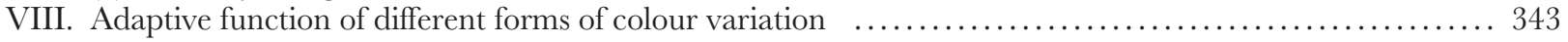

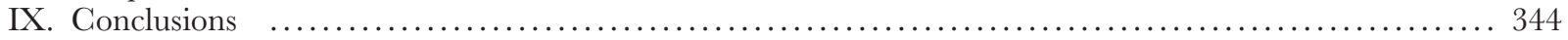

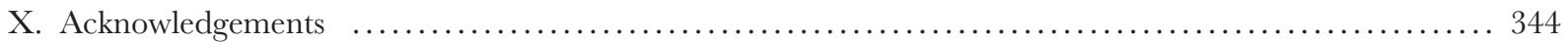

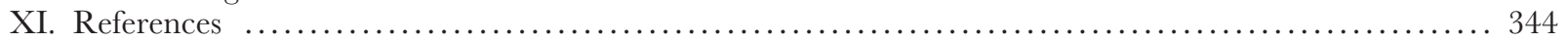

\section{INTRODUCTION}

For decades, evolutionary biologists have been interested in the causes and consequences of phenotypic variation. A major focus of research is to understand the role of conspicuous ornaments in sexual selection processes, particularly on how the degree of male extravagance honestly signals aspects of quality to females (Andersson, 1994). The model 'selection for a handicap', proposed by Zahavi (1975), has been particularly inspiring. His provoking idea was that selection favours individuals who exhibit a secondary sexual character that reduces their relative survival prospects. Sex traits are costly to produce, maintain or wear implying that only the best males can afford these costs and as such, that the display of such traits signals male quality honestly to potential mates and competitors. The benefits in terms of mating success can outweigh the costs of signalling only in the higher-quality males for whom the costs of displaying an ornament are relatively lower compared with males of poorer quality, i.e. the increase of one signalling unit entails more costs to low- than to high-quality males (Zahavi, 1977; Getty, 2006). Subsequently, empiricists have devoted efforts to demonstrate that sexual ornaments are more costly to produce or wear than non-sexual traits, particularly in terms of body condition (Cotton, Fowler \& Pomiankowski, 2004). However, the costs of many sexual traits remain elusive, particularly those of melanin-based colouration which could be taxon specific (Stoehr, 2006).

The expression of melanin-based colouration has been found repeatedly to be strongly genetically controlled and only weakly sensitive to the environment and to variation in body condition (e.g. Hill \& Brawner, 1998; Roulin, Richner \& Ducrest, 1998) thereby raising the question of how melanin-based secondary sexual characters can honestly signal quality (e.g. Badyaev \& Hill, 2000). Interestingly, this type of heritable colouration is frequently associated with phenotypically plastic traits, such as physiology and behaviour, to similar degrees as weakly heritable traits such as carotenoid-based colouration for which expression is strongly sensitive to variations in body condition and environmental conditions (Hadfield \& Owens, 2006). For instance, in salmonids artificial selection for the differential regulation of glucocorticoids indirectly induced a micro-evolutionary change in the extent to which the fish were melanic (Kittilsen etal., 2009). Cross-fostering experiments in the barn owl (Tyto alba) (Roulin \& Ducrest, 2011) and the tawny owl (Strix aluco) (Piault et al., 2009) also showed that melanin-based colouration is genetically correlated with numerous phenotypically plastic traits. Similar results are currently being accumulated in different taxa (birds: Kim et al., 2013; fish: Wedekind et al., 2008; Marie-Orleach et al., 2014; insects: Armitage \& Siva-Jothy, 2005), strengthening the claim that melanin-based colouration covaries with phenotypically plastic traits such as immunity, body mass and hormone levels, even in cases in which the expression of this type of colour trait is not, or is only weakly, sensitive to body condition but is strongly genetically inherited. In other words, whether individuals are in good condition (healthy, well fed, whether they invest high or low effort in activities such as reproduction), they produce their genetically programmed colour trait. Because melanin is the most common pigment in animal integuments and can be responsible for striking ornamentation used in mate choice (Kingma et al., 2008), these observations are likely to be applicable to many organisms.

My goal here is to review the various mechanisms generating covariation between melanin-based colouration and phenotypically plastic traits to understand the evolution, maintenance and adaptive function of colour variation. In this context, I review current evidence for melanin-based traits as criteria in mate choice. I then survey the literature on the cost of producing, maintaining and wearing/displaying melanin-based colouration. I finally discuss the possibility that selection can favour a genetic linkage between 
colouration and other phenotypic attributes. I conclude that several mechanisms can explain why melanin-based colouration is often correlated with other traits, such as body condition.

\section{DEFINITION OF BODY GONDITION AND CONDITION-DEPENDENGE}

Since the proposition by Zahavi (1975) that a sex trait can honestly reveal quality, researchers have invested efforts to demonstrate that secondary sexual characters are costly to produce or maintain or are susceptible to wear (Johnstone, 1995). Although Zahavi's (1975) verbal model and the subsequent mathematical formalisations of it considered signalling costs in terms of viability, empirical studies have, for practical reasons, focused on proxies of viability, such as body condition, and on covariation between condition and sex ornaments. The temptation is therefore to assume that the non-experimental observation of covariation between the degree of colouration and aspects of body condition supports the hypothesis that the expression of colouration is sensitive to variation in body condition and thereby fits with the handicap principle (Guindre-Parker \& Love, 2014). Because such covariation can also be explained by alternative hypotheses, it is important first to define clearly the terms 'body condition' and 'condition-dependence'.

\section{(1) Body condition}

In the context of sexual selection studies, the term 'body condition' has often been considered to equate to immunocompetence (Hamilton \& Zuk, 1982), resistance to oxidative stress (von Schantz etal., 1999) or body mass corrected for body size. In fact, body condition should refer to any phenotypic trait that is directly related to health, viability or fertility. Following Hill (2011, p. 625), body condition refers to 'the relative capacity to maintain optimal functionality of vital systems within the body'. This definition encompasses both genotypic and phenotypic traits that allow individuals to withstand environmental challenges. As a result, condition can depend not only on external influences, such as the amount of resources available to an individual or the number and virulence of parasites, but also on the intrinsic ability to face these external factors (i.e. on genotype $\times$ environment interactions). As emphasised by Hill (2011), condition can therefore not be equated with the amount of stored resources (e.g. fat or essential nutrients, such as carotenoids). Furthermore, because some individuals may invest more resources in one body condition component than in other components and because different body condition components are traded off against each other, the extent to which individuals invest in one single component does not necessarily equal fitness.

\section{(2) Condition-dependence}

The study of the adaptive function of variation in sexual signals frequently uses the term 'condition-dependence'.
However, it is often unclear whether 'condition-dependence' implies that the expression of a colour trait is causally affected by variation in body condition or whether a colour trait is correlated with body condition. Condition-dependent traits allow individuals to signal body condition (i.e. the overall capacity to maintain optimal functionality of body systems) or only some aspects of body condition that may be otherwise imperceptible. Understanding the underlying mechanisms that generate covariation between a secondary sexual character and body condition is crucial for identifying the adaptive function of variation in sex traits. Hill (2011) proposed that ornaments could signal body condition if $(a)$ resources are traded off between physiological pathways and ornament production, $(b)$ a regulatory agent necessary for ornament expression depresses a vital physiological process, $(c)$ ornament production requires a product of a vital physiological process, and $(d)$ pathways are shared between ornament production and vital physiological processes. Because many researchers assume that the expression of ornaments should be costly in terms of body condition, I distinguish above two distinct cases for covariation between body condition and colouration, namely where body condition causally affects the expression or display of colouration (condition-dependent signalling) and where it does not have this causal effect (condition-related signalling).

(1) Condition-related signalling: this term should be used when the degree of colouration is correlated with aspects of body condition, i.e. the overall capacity to maintain the optimal functionality of body systems. This definition does not necessarily imply that variation in body condition causally affects the expression of colouration because it includes other indirect causes resulting in covariation between condition and colouration. Covariation between body condition (or aspects of body condition) and colouration can be of genetic or environmental origin, regardless of the relative importance of these two factors in determining colour expression. Genetic determinism of covariation can be the outcome of linkage disequilibrium of melanogenic genes and genes altering body condition or to pleiotropic genes that simultaneously affect colouration and body condition. Environmental determinism can occur through external factors that affect both body condition and the expression of colouration.

(2) Condition-dependent signalling: this term should be used when body condition causally affects the expression, maintenance or display of an ornament. It can be subdivided into three categories: (i) Condition-dependent expression. This term implies that variation in body condition causally alters the expression of colouration. Only an experimental manipulation of body condition can firmly demonstrate that the expression of colour traits is condition-dependent. As a corollary, even if body condition has a direct impact on the expression of a colour trait, this does not exclude that the covariation between colouration and body condition also has a genetic component. For instance, an association between colouration and body mass can occur if body 
mass affects the expression of colouration (e.g. by trading off resources or energy) or if the genes involved in the expression of colouration pleiotropically affect body mass. Note that manipulating the hormones, metabolites or nutrients implicated in melanogenesis cannot demonstrate that the expression of colouration is condition-dependent. Indeed, these molecules may participate or are required in the elaboration of colour traits, or genes involved in the elaboration of sexual signals may pleiotropically regulate hormones. Experimental tests of condition-dependent expression should manipulate trade-offs in the allocation of resources between competing demands, e.g. sexual signalling and reproduction. (ii) Condition-dependent maintenance. This term defines cases in which variation in the degree of colouration is directly related to the physiological or physical maintenance of colour patches. For instance, colouration can fade due to abrasion and protecting colour patches can rely on specific behaviour or the deposition of substances, mechanisms that can be condition-dependent because they require continued and substantial effort, resources and energy. Note that body condition can also have a genetic component. (iii) Condition-dependent display. Some ornaments must be displayed to be informative. Displaying ornaments can require specific behaviours that are costly to sustain, implying that the full display of an ornament can be condition-dependent.

\section{MELANIN-BASED GOLOURATION AS A CRITERION IN MATE CHOICE}

Although melanin-based colouration is assumed to play a role in mate choice, this statement is often based on indirect evidence, such as assortative pairing or darker individuals breeding earlier in the season. Several experimental approaches have allowed more conclusive results to be obtained.

Presentation of differently melanised decoys to sexually active individuals in butterflies (Pieris occidentalis, $P$. protodice, Colias philodice eriphyle) showed that males court pale females preferentially over dark ones (Wiernasz, 1995; Ellers \& Boggs, 2003). In another study, digitally animated males displaying different levels of melanism were presented to sexually active livebearing variable platyfish (Xiphophorus variatus). The results showed that there was no preference for males displaying small or large black tail spots (Culumber \& Rosenthal, 2013).

Another approach involved the manipulation of melanin-based colouration. By changing the length of the black beard in the bearded tit (Panurus biarmicus), Hoi \& Griggio (2008) showed that females spent more time with males that had an elongated rather than a shortened beard. Other studies have found support for a preference for darker melanic mates, but in contrast to Hoi \& Griggio's (2008) study, these experiments used only darkened individuals but did not compare with individuals with a reduced intensity of melanin-based colouration (barn swallow Hirundo rustica: Safran et al., 2005), or reduced the number of black feather spots but did not have a treatment in which spots were artificially added (barn owl Tyto alba: Roulin, 1999; Roulin \& Altwegg, 2007). As discussed in Roulin (1999), these experiments are interesting but the experimental design constrains the conclusions that can be drawn.

In another series of experiments, differently coloured males were presented to females in mate-choice trials, and showed that melanism is a mate-choice criterion (Cooke, Mirsky \& Seiger, 1972; Burley, 1977; Houtman \& Falls, 1994; Hughes et al., 1999; Fernandez \& Morris, 2008; Moyaho et al., 2010; Pryke, 2010; Svensson et al., 2010). These experiments however, could not rule out the possibility that mate choice was exerted on phenotypic traits (e.g. behaviour or body size) correlated to the degree of melanism.

Detailed correlative field studies showed that males with larger melanin-based ornaments mate more quickly or have more mates than do males with smaller ornaments (Kingma et al., 2008). However, as in the mate-choice trials, whether these findings result from females choosing males according to male melanin colouration is not clear.

The above studies support the hypothesis that melanin-based colouration is often a criterion in mate choice, although further work is needed to substantiate this and allow generalisations across taxa. Note that mate choice does not always favour the darkest individuals but that in some species, lighter coloured individuals are preferred. Furthermore, mate choice may not always be directional. Different individuals may have different mating preferences or the same individual may modify its preference depending on environmental or social conditions (Roulin \& Bize, 2007). Sexual selection can be context-dependent.

Mate choice based on the degree of melanin-based colouration can provide direct material benefits and/or indirect genetic benefits. Three mechanisms could account for the direct fitness benefits of choosing a mate based on melanin-based colouration. First, differently coloured individuals could exploit alternative habitats because they are adapted to specific environmental conditions (Leimar, 2009). Therefore, the choosy sex may prefer to mate with individuals that are locally adapted to the prevailing environmental conditions. Second, if the expression of melanin-based colouration is condition-dependent, darker individuals may be in better condition and therefore better able to provide parental care. Third, in species with parental care, the degree of melanism may be genetically linked to investment in various aspects of parental care including protection of offspring against predators (Quesada \& Senar, 2007; Kivanova, Horakova \& Exnerova, 2011; Da Silva et al., 2013), feeding rates (Roulin et al., 2001a; Siefferman \& Hill, 2003; Olsen et al., 2010) or territory quality (Hasegawa etal., 2014). Regarding indirect fitness benefits, choosing a mate based on the degree of melanin-based colouration could allow the choosy sex to produce offspring of higher genetic quality (sexy sons). In fish, in vitro fertilisation experiments showed that offspring born from blacker parents were more resistant to various sources of stress (Wedekind et al., 2008; Jacob etal., 2010; Marie-Orleach etal., 2014) and artificial selection showed that the size of black eumelanic 
spots is genetically correlated to resistance to stress (Kittilsen etal., 2009). In birds, cross-fostering experiments showed that the expression of several offspring phenotypes is related to the degree of parental melanism (Bize et al., 2006; Roulin \& Ducrest, 2011; Remes \& Matysioková, 2013).

\section{PROXIMATE MEGHANISMS OF THE GOVARIATION BETWEEN MELANIN-BASED COLOURATION AND BODY GONDITION}

Covariation between melanin-based colouration and other phenotypic traits can arise because colouration is costly to produce, maintain or is susceptible to wear, or it can arise through shared biochemical pathways between melanogenesis and body condition (i.e. pleiotropic genes and/or hormones involved in melanogenesis affect body condition). Physical linkages on the same chromosome of genes encoding for melanin-based colouration and body condition (McKinnon \& Pierotti, 2010) may also contribute to this covariation.

\section{(1) Cost of producing melanin-based colouration}

Melanin-based colouration can be costly to produce because it demands energy and/or resources (Tables 1 and 2). As a consequence of these costs, the production of melanin pigments can be influenced by changes in body condition. However, organisms deposit melanins in different integumentary structures, which may strongly affect the relationship between body condition and colouration. For example, in some animals, such as fish, frogs, reptiles and squids, colouration can change very quickly, on the order of seconds, because of the existence of neuronal- or hormonal-sensitive pigmented chromatophores penetrating the skin from the muscles (Grether, Kolluru \& Nersissian, 2004; Larsen et al., 2012; Rodgers etal., 2013). This allows animals to modify their colouration to sudden modification in the environment or social interactions (as found in reptiles, Grether et al., 2004; Rowe et al., 2013 and in fish, Rodgers et al., 2013; Ruell et al., 2013). This may obscure any relationship between body condition and colouration. If producing extra melanin is energetically costly, animals may increase food intake rates as shown in guppies (Poecilia reticulata) (Rodgers et al., 2013). Therefore, in these animals variation in body condition measured at any point in the life cycle may be correlated with body colouration, but its signalling function may also vary with the social and environmental context (Greenberg, 2002).

Colour changes are not necessarily related to changes in melanin production but to where it is allocated. When colourful body structures, such as hair in mammals or skin cells in humans, are replaced regularly, colouration may also correlate with variations in body condition measured at any time of the life cycle because variations in body condition can constantly affect colour production. In other organisms, coloured body structures such as feathers and cuticles are inert and replaced only a few times throughout a lifetime. As a consequence, the expression of melanin pigments can be influenced by the environment and by body condition at the specific times when these structures are produced. Thus, if producing melanin pigments is energetically costly (Table 1) or requires specific nutrients (Table 2), the degree of colouration should mainly correlate with body condition measured at the specific time of pigment production, rather than at an earlier or later stage, assuming that melanin is not stored for long periods of time before being transported to the integument (Tarafder et al., 2014).

Table 1. Effect of manipulating body condition on the expression of melanin-based colouration. Studies that reported a significant effect are shown in bold. Brood size was experimentally enlarged or reduced to test whether sibling competition (in nestlings) or parental effort (in adults) affects colouration. The sensitivity of colouration to other environmental factors has been experimentally tested by manipulating endo- or ectoparasitism, food quantity or quality, and temperature

\begin{tabular}{|c|c|c|}
\hline & Species & References \\
\hline \multicolumn{3}{|l|}{ Invertebrates } \\
\hline Food quantity & Paper wasp (Polistes dominulus) & Tibbetts (2010) \\
\hline Temperature & Small white (Pieris rapae) & Stoehr $(2010)$ \\
\hline Temperature & Southern green stink bug (Nezara viridula) & Musolin, Tougou \& Fujisaki (2010) \\
\hline Drought-stress & Satyrine butterfly (Pararge aegeria) & Talloen, van Dyck \& Lens (2004) \\
\hline \multicolumn{3}{|l|}{ Vertebrates } \\
\hline Brood size in nestlings & Kestrel (Falco tinnunculus) & Piault, van den Brink \& Roulin (2012) \\
\hline Brood size in nestlings & Barn owl (Tyto alba) & Roulin et al. (1998) \\
\hline Brood size in nestlings & Alpine swift (Apus melbae) & Bize et al. (2006) \\
\hline Brood size in nestlings & Tawny owl (Strix aluco) & Emaresi et al. (2013) \\
\hline Brood size in adults & Alpine swift (Apus melbae) & Bize et al. (2006) \\
\hline Endoparasitism & American goldfinch (Carduelis tristis) & McGraw \& Hill (2000) \\
\hline Endoparasitism & House finch (Carpodacus mexicanus) & Hill \& Brawner (1998) \\
\hline Ectoparasitism & Great tit (Parus major) & Fitze \& Richner (2002) \\
\hline Food quantity & House sparrow (Passer domesticus) & McGraw et al. (2002) \\
\hline Food quantity & Brown-headed cowbirds (Molothrus ater) & McGraw et al. (2002) \\
\hline Food quality & House sparrow (Passer domesticus) & Gonzalez et al. (1999) \\
\hline
\end{tabular}


Table 2. Manipulation of nutrient levels to determine whether the expression of melanin-based colouration is affected by access to nutrients. - and + indicate that dietary supplementation (or reduction in Poston et al., 2005) of a given nutrient (calcium, tyrosine and phenylalanine) leads to a decrease or increase in melanin-based colouration, respectively; 'mixed results' means that the effect of a reduction in tyrosine and phenylalanine decreased the intensity (darkness) of melanin-based colouration but had no effect on the size of melanic patch

\begin{tabular}{|c|c|c|c|}
\hline Nutrient & Species & Effect & References \\
\hline Dietary calcium & House sparrow (Passer domesticus) & - & Stewart \& Westneat (2010) \\
\hline Dietary calcium & House sparrow (Passer domesticus) & - & Stewart \& Westneat (2013) \\
\hline Dietary calcium & House sparrow (Passer domesticus) & + & McGraw (2007) \\
\hline Tyrosine and phenylalanine & House sparrow (Passer domesticus) & Mixed results & Poston et al. (2005) \\
\hline Tyrosine and phenylalanine & Domestic cat (Felix catus) & $\begin{array}{l}\text { + on eumelanin } \\
\text { - on pheomelanin }\end{array}$ & Yu, Rogers \& Morris (2001) \\
\hline
\end{tabular}

If colour differences are due to variation in the degree of depigmentation rather than pigmentation, it may be difficult to propose a priori predictions regarding whether poor body condition should lead to a reduction or augmentation of melanin production. For instance, female eiders (Somateria mollissima) displaying larger white feather patches lost less body mass and maintained a potent immune defence during reproduction compared with individuals showing smaller white patches (Hanssen, Folstad \& Erikstad, 2006). Furthermore, in some species individuals become less pigmented with age, whereas the opposite is observed in other species (Meunier etal., 2011). A possible combination of these mechanisms (i.e. pigmentation and depigmentation being signals of quality) can result in even more complex patterns of colouration. In the barn owl, between the first and second years of age, males and females become lighter reddish pheomelanic, the size of the black feather spots increases in females, and the number of black spots decreases in males (Dreiss \& Roulin, 2010).

These different predictions on how colouration is expected to covary with body condition have not yet been tested, and to date, very few experimental studies have been performed to test whether variations in body condition that are present at the time when pigments are produced alter the expression of melanin-based colouration. Whereas four experimental studies in invertebrates reported a significant effect of body condition on colour expression, similar findings in vertebrates are restricted to a limited number of species (Table 1). Therefore, covariation between melanin-based colouration and body condition may not always be explained by a causal effect of body condition on the expression of melanin-based colouration (see Section II). A condition-dependent component may be taxon specific (Stoehr, 2006) with polyphenism being relatively frequent in invertebrates in which discrete variation in colouration can be environmentally determined (Leimar, 2009; Musolin et al., 2010; Johansson \& Nilsson-Örtman, 2013).

Below I review four potential costs associated with the production of melanin-based colouration: the cost of producing melanin pigments; the cost of switching from pheomelanin to eumelanin production; the cost of distributing pigments on the body; and the cost of producing the necessary integumentary structures to host melanin pigments.

\section{(a) Cost of producing melanin pigments}

Condition-dependent colour expression can occur if the production of melanin pigments is costly. Because of the difficulty in measuring the concentrations of eumelanin and pheomelanin pigments and the expression levels of melanogenic genes, little is known about the role of body condition on melanogenesis per se. A recent study performed in nestling tawny owls showed that the manipulation of brood size did not alter the expression levels of nine genes belonging to the melanogenesis pathway (Emaresi etal., 2013). The absence of such an effect could be explained by the brood-size-manipulation experiment having little impact on body condition (this study was performed in a year with prime feeding conditions; A. Roulin, personal observations). However, in the same study body condition, measured as the residuals of body mass on wing length, was negatively related to the expression levels of one of the nine genes measured in 151 nestlings at 11 and 25 days of age $(P$-value $=0.009$ for ASIP; 0.10 for PC1 /3; 0.93 for SLC7A11; 0.63 for MC1R; 0.24 for PCSK2; 0.39 for TRR; 0.84 for MITF; 0.64 for POMC and 0.15 for TYRP1) indicating that ASIP may be expressed at lower levels in nestlings with better body condition. Further studies are required to identify melanogenic genes for which expression is increased or decreased when the body condition improves.

A few studies investigated whether the expression of melanin-based colouration requires nutrients. If those nutrients are found in limited quantities in nature, only the best individuals may be able to acquire them in sufficient quantities to produce large or intense melanin ornaments. However, the few studies available reported varying results (Table 2). For example, house sparrows (Passer domesticus) fed a diet containing reduced levels $(50 \%)$ of phenylalanine and tyrosine produced a black bib of similar size to control birds but with lighter-coloured feathers (Poston et al., 2005). In this bird, a reduction in dietary content of these amino acid precursors to melanin does not switch off feather production of melanin pigments (because bib size was unaffected), but instead reduces the amount of melanin produced (leading to lighter coloured feathers) or causes a switch from the production of eumelanin to pheomelanin as shown in the domestic cat (Felix catus) (Yu et al., 2001). It remains to be established whether 
tyrosine is naturally available only in limited quantities, leading the expression of intense melanin-based colouration to be condition-dependent. Even if the experimental manipulation of dietary tyrosine, calcium, or any other nutrient, alters the expression of melanin-based traits, this does not necessarily imply that any inter-individual variation in colouration is due to differential access to these nutrients under natural conditions because there might not be sufficient inter-individual variation present in the acquisition of these nutrients.

\section{(b) Switch from pheomelanin to eumelanin production}

Variation in melanin-based colouration can be due to differential deposition of the pigments eumelanin and pheomelanin, which are responsible for black/grey and rusty/reddish/brownish colourations, respectively. Even if the total amount of melanin pigments is not sensitive to variation in body condition, the ratio of pheomelanin to eumelanin pigments may be modified. These two pigments share part of their biochemical cascade with the rate-limiting enzyme (tyrosinase) transforming tyrosine to eumelanin unless cysteine is available, in which case pheomelanin is produced (Walker \& Gunn, 2010). If these different pathways of melanogenesis entail different energetic costs, it is possible that the transition from eumelanogenesis to pheomelanogenesis could depend on body condition, but this remains to be studied in detail. This mechanism may apply to species that vary from reddish pheomelanic to black eumelanic (e.g. back colouration in the pied flycatcher Ficedula hypoleuca). Accordingly, in the kestrel (Falco tinnunculus), a correlative study showed that in years with abundant food supplies male nestlings developed a greyer rump (i.e. more eumelanic) than in poor years, during which they developed a browner rump (i.e. more pheomelanic) (Fargallo et al., 2007a). In this case, good conditions appeared to favour the production of eumelanin over pheomelanin.

\section{(c) Cost of distributing pigments on the body}

The cost of melanin-based colouration may not lie in the quantity of melanin pigments produced but rather in the way these pigments are arranged. Because melanins are mainly produced in the skin, it is unlikely that the costs associated with melanin distribution derive from transport costs, as suggested for carotenoids (Hill et al., 1994). For example, in paper wasps (Polistes dominulus), access to food resources does not modify the amount of black melanin pigments, but the way in which these pigments are distributed on the body. Wasps fed a high-caterpillar diet showed more black facial patches, a trait that is used as a signal in social interactions (Tibbetts, 2008), than wasps fed a low-caterpillar diet (Tibbetts, 2010). Another example is the great tit (Parus major), in which the regularity of melanin-based patches (i.e. immaculateness) entails costs, potentially explaining why individuals displaying regular head and body patterns are socially dominant (Ferns \& Hinsley, 2004). These authors showed that an experimental decrease in cheek immaculateness induced more social competitive interactions; in cross-fostered nestlings, Remes \& Matysioková (2013) showed that nestlings responded more intensely to an immune challenge of phytohaemagglutinin when their biological and foster parents displayed a higher degree of cheek immaculateness. From a proximate view, the cost of producing an immaculate cheek could be explained by feather damage (Ferns \& Hinsley, 2004). Alternatively, correctly assembling melanin pigments, coordinating the expression of a given gene in multiple cells located in the same or in different body regions, as well as avoiding stochastic variation (or noise) in gene expression, may also be costly (Eldar \& Elowitz, 2010; Less etal., 2011; Wang \& Zhang, 2011; Fabricant et al., 2013).

\section{(d) Structure of the integument}

Other mechanisms beyond the cost of melanin production and distribution can be invoked to explain why variation in body condition could alter the expression of melanin-based colouration. Variations in colouration can be caused by a modification of the structure in which pigments are embedded (feathers, hair, cuticle, scales), melanoblast migration and differentiation as well as melanosome structure (Fitzpatrick, 1998; Roulin \& Ducrest, 2013; D’Alba etal., 2014). For instance, poor body condition can negatively affect feather microstructure (DesRochers et al., 2009; Broggi et al., 2011) and, as a consequence, modify colouration, even if the amount of pigments is not altered (D'Alba et al., 2014). Assuming that melanin production occurs in a fixed amount of time, variations in feather growth rates (Dawson etal., 2000) may also determine the surface coloured by melanin pigments (Vagasi, Pap \& Barta, 2010). If feathers grow at a faster rate, pigments may be deposited over a larger surface with the consequence that these patches are less intensely coloured. Unfortunately, the timing of melanogenesis has been poorly studied (Lin et al., 2013).

The size of a melanic patch is susceptible to changes in body volume in certain species, and because birds are a prime example of this, I focus on this group of animals. Birds' lungs and air sacs represent up to $14-22 \%$ of their total body volume (Dubach, 1981). The volume occupied by gas in the lungs and air sacs can be actively regulated (Hasley et al., 2005) and varies according to body position (Malka et al., 2009). Furthermore, birds can actively adjust the volume of air in the plumage layer (Stephenson, 1993). Therefore, variations in body surface area could be responsible for both between- and within-individual variations in the area covered with a colour trait. Feather arrangement may also lead to variations in the size of feather patches (Adamik \& Vanakova, 2011). For instance, Fitze \& Richner (2002) showed that ectoparasites had a negative impact on the size of the ventral breast band in great tits. However, it is unclear whether parasitism induced tits to produce fewer melanic and more yellow feathers or whether parasitism modified the surface covered by black (and perhaps yellow) feathers. Obviously, this mechanism may not be restricted to birds. 
Table 3. Studies testing whether an experimental increase in the size of status signals (black badges) induces social interactions to test its honesty as a signal of quality

\begin{tabular}{lll}
\hline \hline Species & Result & References \\
\hline Paper wasp (Polistes dominulus) & More social interactions & Tibbetts \& Dale (2004) \\
Wasp (Parischnogaster mellyi) & More social interactions & Beani \& Turillazzi (1999) \\
Harris sparrow (Zonotrichia quereula) & More social interactions & Rohwer (1977) \\
House sparrow (Passer domesticus) & More social interactions & Møller (1987) \\
House sparrow (Passer domesticus) & No effect & Gonzalez et al. (2002) \\
Dark-eyed junco (funco hyemalis) & No effect & Grasso, Savalli \& Mumme (1996) \\
White-crowned sparrow (Zonotrichia leucophrys gambelii) & Fewer social interactions & Fugle \& Rothstein (1987) \\
\hline \hline
\end{tabular}

\section{(2) Cost of maintaining melanin-based colouration}

Numerous secondary sexual characters are costly to maintain. For instance, parasites, such as mallophaga and bacteria, preferentially consume depigmented over pigmented body parts (Kose \& Møller, 1999; Ruiz-De-Castaneda etal., 2012). Additionally, melanin pigments improve integument resistance to physically abrasive agents, such as ultraviolet solar radiation or dust (Bonser, 1995). Abrasion of the integument containing melanins, particularly when it cannot be continuously substituted, as with feathers, cuticle or scales, may impose maintenance costs in terms of energy, resources, or time. For instance, feather abrasion can explain why colouration fades as feathers age, i.e. they have experienced a longer period of abrasion than freshly renewed feathers (Delhey etal., 2010). This is particularly striking in diurnal compared with nocturnal species (A. Roulin, personal observations). Variations in colouration can therefore depend on the ability to maintain a high-quality integument. This can involve not only the speed of replacing old feathers, hair or cuticle (McGregor, 1988; Dawson et al., 2000; Serra, 2001; Vagasi et al., 2010; Saino et al., 2013a) but also the ability to protect, clean and spread dermal protective substances on the integument, which can be energetically costly and time consuming. These substances can both protect the body against pathogens (Martin-Vivaldi et al., 2010 but see Pap etal., 2010) and wear (Moreno-Rueda, 2011) and modify colouration (Piersma, Dekker \& Sinninghe Damsté, 1999; Saikawa et al., 2004). In birds, for instance, variations in body condition can affect the amount and quality of uropygial gland secretions (Reneerkens et al., 2008) and, in turn, melanin-based colouration (Piault et al., 2008).

\section{(3) Cost of wearing/displaying melanin-based colour traits}

(a) Social control of the honesty of melanin-based colouration as a signal of body condition

Wearing different versions of a colour trait can differentially affect the behaviour of conspecifics. In a number of animals, black badges serve as signals of status, with individuals displaying larger badges commonly being socially dominant (Santos, Scheck \& Nakagawa, 201 1; Diep \& Westneat, 2013). Experimental studies showed that conspecifics challenge large-badged individuals to test whether they are truly superior in social interactions (Senar \& Camerino, 1998; Diep \& Westneat, 2013). Therefore, the size of black badges could be positively correlated with body condition if only higher-quality individuals are able to sustain the cost of social challenges or if a large badge allows them to win most social challenges easily or obtain more food resources (Nakagawa et al., 2008). However, because social interactions are stressful, displaying large badges may induce a reduction in body condition, which could be compensated by higher reproductive success. It is therefore unclear whether body condition should always be positively associated with the size of badges of status, potentially explaining why such associations can vary among studies (Nakagawa et al., 2007). Finally, displaying a melanin-based trait may require specific associated behaviours (e.g. dancing) that are energetically costly and time consuming.

When badge size was experimentally manipulated, in most cases, the display of a larger melanin-based trait induced an increase in the number of social interactions (Table 3). It follows that the honesty of melanin-based traits as signals of quality can be ensured by social interactions. A key question is whether such a mechanism is restricted to so-called 'badges of status', such as facial black patches in wasps or the black bib in the house sparrow and siskin (Carduelis spinus), or whether it also applies to other melanin-based colour traits. It is plausible that it applies more widely in most species, blacker individuals being more aggressive and more sexually active (Ducrest, Keller \& Roulin, 2008, but see van den Brink et al., 2012 who found barn owls displaying smaller black spots to be more aggressive than individuals with larger black spots).

\section{(b) Positive frequency-dependent selection}

Frequency-dependent selection is a major mechanism that can explain the maintenance of genetic polymorphisms (Maynard-Smith, 1982), including those associated with colour variations (Losey et al., 1997; Svensson, Abbott \& Hardling, 2005). Typically, the fitness of coexisting colour morphs is equal at the so-called 'equilibrium frequency'. As a consequence, an increase in the frequency of one morph beyond this equilibrium frequency will impair the fitness of individuals displaying this morph, whereas the fitness of the morphs that decreased in frequency will increase until the equilibrium frequency is reattained. As a consequence, covariation between colouration and body condition may 
be transient and vary in relation to the frequency of negative interactions among morphs, as shown in lizards (Sinervo, Bleay \& Adamopoulou, 2001; Vercken, Clobert \& Sinervo, 2010). To understand better how this mechanism may work, consider the example of the ruff (Philomachus pugnax) in which the dark morph is more aggressive than the pale morph (Hill, 1991). If the frequency of the dark morph increases, antagonistic interactions between dark individuals will increase, which may negatively affect not only their reproductive success (Hugie \& Lank, 1997) but also their body condition. As a consequence, if dark individuals become too frequent, their condition may decrease relative to paler conspecifics, for which body condition may improve due to reduced antagonistic interactions with dark individuals, who are preoccupied with fighting against each other. Similarly, if predators preferentially attack the most common morph of a colour-polymorphic prey species because this morph is most familiar, the higher predation risk on this morph may result in decreased body condition. Unfortunately, the general applicability of this mechanism cannot be evaluated, because the impact of the frequency of colour variants on the covariation between colouration and body condition has rarely been considered in the literature.

\section{(c) Negative frequency-dependent selection}

A colour variant can achieve a higher fitness than the most common colour morph when rare (Ayala \& Campbell, 1974). This so-called 'negative frequency-dependent selection' has been demonstrated in the context of sexual selection, with males that display a rare colouration enjoying a mating advantage (Hughes etal., 2013). With respect to predator-prey interactions, this selective process is sometimes termed 'apostatic selection', with individuals displaying a rare morph not being recognised as potential prey by predators or as a potential predator by prey (Bond, 2007). Therefore, individuals displaying a rare morph may be in better condition than those with the most common colour pattern, either because they enjoy higher foraging success than the most common morph or because they are attacked by predators less often, as shown in several experimental studies (Olendorf et al., 2006; Iserbyt et al., 2013).

\section{(d) Local adaptation to heterogeneous environments}

In a number of animals, melanin-based colourations are associated with specific adaptations to alternative environmental conditions. Local adaptation is a major mechanism that explains the evolutionary stability of colour polymorphism in spatially heterogeneous environments in which one morph is adapted to a given habitat and another morph is adapted to a different habitat (Bell, 2010). Therefore, if a given colour pattern allows individuals to perform particularly well in a specific environment (Mills et al., 2013), individuals displaying a different colouration may suffer reduced condition when they exploit the environment to which they are not adapted. As a consequence, covariation between colouration and body condition may differ between environments because in each habitat one morph thrives in contrast to the other less well-adapted morph. For instance, in a case in which melanin colouration plays a significant role in camouflage (Caro et al., 2012; Fargallo \& Forstner, 2012), differently coloured individuals may forage on different food sources (Charter etal., 2012) or be predated by different species (Surmacki, Ozarowska-Nowicka \& Rosin, 2013). As a consequence, body condition may become associated with colouration if food that is commonly consumed only by individuals displaying a specific colouration becomes less abundant due to stochastic processes or cyclic population crashes.

Melanin pigments can play an important role in thermoregulation, particularly in ectotherms. Dark-coloured integuments capture energy from the sun more effectively than pale colourations (Clusella-Trullas et al., 2008). Therefore, depending on how differently coloured individuals are spatially located in relation to solar radiation, they may potentially show colour-specific variation in body condition related to thermoregulatory ability (Castella et al., 2013). This implies that covariation between melanin-based colouration and aspects of body condition can be the result of colouration itself, a phenomenon that may become increasingly frequent with global warming (Roulin, 2014).

\section{(4) The role of pleiotropy in generating covariation between colouration and body condition}

Covariation between melanin-based colouration and indices of body condition is often considered to occur because some individuals (e.g. those that are dark coloured) are of higher overall quality than others (e.g. those that are pale coloured). For instance, if dark individuals perform better with respect to a given body condition index than do pale conspecifics, the former are then assumed to achieve higher fitness. This may, however, not be true if different colour patterns are associated with selectively equivalent strategies that coexist through frequency-dependent or disruptive selection (e.g. local adaptation). To cope with specific environmental situations natural selection may select alternative strategies (Maynard-Smith, 1982) that require specific behavioural, physiological or morphological adaptations. If specific combinations of traits are necessary to perform a given strategy, various traits may evolve non-independently from each other. Selection exerted on colouration may be correlated to selection exerted on indices of body condition, generating covariation among morphology, physiology and colouration (Kingsolver \& Diamond, 2011) which can be mistaken for associations with phenotypic quality. Differently coloured individuals may therefore be genetically predisposed to invest differentially in some aspect of body condition, for instance because foraging requires specific combinations of traits such as a dark colouration and large size (Caesar, Ahnesjö \& Forsman, 2007). This implies that if light-coloured individuals are smaller or have a lower body mass than darker conspecifics, they are not necessarily in poorer overall condition and with a lower fitness. Differently coloured individuals may adopt alternative but equally successful life-history strategies, each requiring specific investments 
in different body condition components, physiology or behaviour (Takahashi \& Kawata, 2013). For instance, investment in reproductive activities may be colour-dependent implying that the cost of reproduction induces a change in body condition that differs between dark and pale individuals (Gasparini et al., 2009; Emaresi et al., 2014). Thus, even if one type of colouration is associated with traits that are generally considered to reflect poor condition (and in turn low fitness), the colour-specific regulation of body condition may instead reflect that differently coloured individuals adopt alternative but equivalent strategies in terms of selection. This concept is accepted for the so-called 'colour polymorphic' species, i.e. species for which conspecifics of the same sex and age display a limited number of genetically determined colour morphs (Roulin, 2004). However, it may also apply to other species for which genetically inherited inter-individual variation in colouration is continuous (Iwasa \& Pomiankowski, 1991).

\section{(a) Pleiotropic effects of melanogenic genes}

From a proximate point of view, correlated selection on colouration and body condition can favour linkage disequilibrium between their underlying genes (Gratten etal., 2008) or pleiotropy with genes that have multiple effects by simultaneously regulating colouration and body condition (Ducrest et al., 2008). Genetic correlations between melanin-based colouration and various aspects of body condition have been demonstrated in insects artificially selected for dark or light melanic colouration (Ramniwas etal., 2013) and in vertebrates (Table 4). In birds, cross-fostering experiments, where eggs or hatchlings were swapped between randomly chosen families, have also shown that body condition of offspring raised by foster parents is genetically correlated with the colouration of their biological parents (Roulin et al., 2008b). Thus, covariation between colouration and body condition may occur because differently coloured individuals possess alternative genes that differentially regulate body condition. Even if the expression of colour traits is strongly canalised and hence, under strong genetic control, the expression of pleiotropic melanogenic genes may vary depending on the environmental conditions (Roulin etal., 2011) or life stages (Emaresi etal., 2013). For this reason, covariation between colouration and body condition may be context-dependent (Roulin, 2009) and may thus not always be detected. For instance, covariation between parental colouration and nestling body mass was detected only under prime rearing conditions in the barn owl and tawny owl (Roulin et al., 2008b). Different environments thus may select for differently coloured individuals.

Genes encoding for different expression levels of pleiotropic genes may be considered to be alternative evolutionarily stable strategies. For instance, over-expressing genes that are involved in immune defence may be beneficial only if parasites are abundant and/or virulent (Heeb et al., 1998). Because genes, such as those of the melanocortin system, have many pleiotropic effects (Ducrest et al., 2008), individuals that over-express them may not always be selected for if by doing so they invest resources into a wide range of costly activities, i.e. in activities additional to immune defence. In heterogeneous environments, various patterns of expression levels could be signalled by different colour patterns either because different biological solutions have evolved to cope with a particular environmental situation or because different solutions have evolved to address different environmental conditions (local adaptation). A key question is why a dark rather than pale colouration is associated with high (or low) expression levels of pleiotropic genes. In other words, are darker individuals more immunocompetent in most vertebrates or is the relationship between colouration and immunocompetence species-specific? Indeed, in some species, correlated selection may simultaneously favour a pale colouration and a potent immune system, whereas in other species, it may favour a dark colouration and efficient immune system. Pleiotropy may prevent individuals from cheating, i.e. individuals displaying a given colouration cannot pretend to be in the physiological state of individuals displaying another colouration. This is due to the strong genetic link between colouration and other phenotypes generated by pleiotropic genes that prevents a pale phenotype from adopting the genetically determined 'dark strategy'. Furthermore, cheating is not advantageous because individuals displaying alternative 'colour morphs' do not only differ in colouration but in a suite of phenotypic traits. Because morphs are associated with specific strategies that necessitate a battery of adaptations, changing one of the traits (i.e. cheating) should not be advantageous if it is not accompanied by changes in the correlated phenotypes. This may be a reason why pleiotropy for sexually selected traits is maintained even when facing strong selection.

\section{(b) Hormone profiles}

Folstad \& Karter (1992) were the first to propose a potential physiological mechanism explaining why colouration is correlated with indices of body condition. They suggested that only high-quality individuals cope with the reduction in body condition induced by testosterone that is required to produce conspicuous sexual ornaments. Subsequently, many researchers manipulated testosterone levels to test whether the expression of melanin-based colouration is testosterone-dependent (Buchanan etal., 2001). However, even if melanin-based colouration is correlated with testosterone levels (Bubenik \& Bubenik, 1985) and experimental administration of testosterone increases melanin-based colouration (Fargallo et al., 2007b), decreases it (Ros, 1999) or accelerates the production of black nuptial integument (Groothuis \& Meeuwissen, 1992; Eising, Müller \& Groothuis, 2006), it does not necessarily prove that variations in natural concentrations of testosterone levels caused by environmental and social factors are responsible for the inter-individual variation in colouration observed in natural conditions. Melanogenic genes may pleiotropically regulate testosterone (Ducrest et al., 2008) so that artificial administration of testosterone alters melanogenesis through feedback loops, whereas an increase in testosterone levels induced by the environment or social interactions may have no effect on melanogenesis. Indeed, in experiments that are typically performed in the 
Table 4. Genetic correlation between melanin-based colouration and body condition. Black colourations are mainly due to eumelanin and reddish colourations to pheomelanin. PHA refers to the T cell proliferative responses to phytohaemagglutinin

\begin{tabular}{|c|c|c|c|}
\hline Species & Relationship & Method & References \\
\hline Invertebrates & Numerous examples & & Wittkopp \& Beldade (2009) \\
\hline Black colouration & Blacker individuals are/have & & \\
\hline Brown trout (Salmo trutta) & More viable & In vitro fertilisation & Wedekind et al. (2008) \\
\hline Brown trout (Salmo trutta) & More resistant to pathogens & In vitro fertilisation & Jacob et al. $(2010)$ \\
\hline Atlantic salmon (Salmo solar) & More viable & In vitro fertilisation & Marie-Orleach et al. (2014) \\
\hline Atlantic salmon (Salmo solar) & Take more time to emerge & In vitro fertilisation & Marie-Orleach et al. (2014) \\
\hline $\begin{array}{l}\text { Rainbow trout (Oncorhynchus } \\
\text { mykiss) }\end{array}$ & Lower cortisol response & Selection lines & Kittilsen et al. (2009) \\
\hline Kestrel (Falco tinnunculus) & Lower body mass & Animal model & Kim et al. (2013) \\
\hline Great tit (Parus major) & Heavier & Cross-fostering & Remes \& Matysioková (2013) \\
\hline Eleonora's falcon (Falco eleonorae) & Lower immune (PHA) response & Cross-fostering & Gangoso et al. (2011) \\
\hline Barn owl (Tyto alba) & Higher antibody response & Cross-fostering & Roulin et al. (2000) \\
\hline Barn owl (Tyto alba) & Higher parasite resistance & Cross-fostering & Roulin et al. $(2001 b)$ \\
\hline Barn owl (Tyto alba) & Lower fluctuating asymmetry & Cross-fostering & Roulin et al. (2003) \\
\hline Barn owl (Tyto alba) & Heavier & Cross-fostering & Roulin et al. $(2008 b)$ \\
\hline Barn owl (Tyto alba) & $\begin{array}{l}\text { Lower stress-induced } \\
\text { corticosterone response }\end{array}$ & Cross-fostering & Almasi et al. (2010) \\
\hline Barn owl (Tyto alba) & Better regulated corticosterone & Cross-fostering & Almasi et al. (2010) \\
\hline Barn owl (Tyto alba) & $\begin{array}{l}\text { Different daily regulation of } \\
\text { corticosterone }\end{array}$ & Cross-fostering & Roulin, Almasi \& Jenni $(2010 a)$ \\
\hline Barn owl (Tyto alba) & $\begin{array}{l}\text { Take longer to erect when placed } \\
\text { on the back }\end{array}$ & Cross-fostering & van den Brink et al. (2012) \\
\hline Barn owl (Tyto alba) & More docile when handled & Cross-fostering & van den Brink et al. (2012) \\
\hline Alpine swift (Apus melba) & Heavier & Cross-fostering & Bize et al. (2006) \\
\hline Alpine swift (Apus melba) & Longer tailed & Cross-fostering & Bize et al. (2006) \\
\hline Alpine swift (Apus melba) & Fledge at an earlier age & Cross-fostering & Bize et al. (2006) \\
\hline Alpine swift (Apus melba) & Grow wings faster & Cross-fostering & Roulin et al. $(2008 b)$ \\
\hline Reddish colouration & $\begin{array}{l}\text { Redder individuals } \\
\text { are/have/produce }\end{array}$ & & \\
\hline Tawny owl (Strix aluco) & Heavier offspring & Cross-fostering & Roulin et al. (2004) \\
\hline Tawny owl (Strix aluco) & Heavier and longer winged & Cross-fostering & Roulin et al. $(2008 b)$ \\
\hline Tawny owl (Strix aluco) & Heavier & Cross-fostering & Piault et al. (2009) \\
\hline Tawny owl (Strix aluco) & Lower body mass & Cross-fostering & Piault et al. (2009) \\
\hline Barn owl (Tyto alba) & Longer tailed & Cross-fostering & Roulin (2006) \\
\hline Barn owl (Tyto alba) & Heavier & Cross-fostering & Roulin et al. $(2008 b)$ \\
\hline Barn owl (Tyto alba) & Grow wings slower & Cross-fostering & Roulin et al. $(2008 b)$ \\
\hline
\end{tabular}

In vitro fertilisation is a traditional design used by ichthyologists to allocate sperm randomly among eggs produced by different females; this design allows researchers to separate the effects of paternal and maternal genotype on offspring body condition. This design prevents females from allocating resources to their eggs differentially in relation to the paternal phenotype. Therefore, any relationship between paternal colouration and offspring body condition should be due to genetic factors. Cross-fostering is a traditional design used by ornithologists; eggs or hatchlings are swapped between randomly chosen nests in order to allocate genotypes randomly among rearing environments. Therefore, any relationship between offspring body condition and colouration of the biological parents should arise because dark parents pass on to their offspring genes that regulate body condition in a different way than genes passed on by pale parents or because of maternal effects. In rainbow trout, Kittilsen et al. (2009) selected fish for low or high cortisol response to stress. They found that after several generations of selection, fish of the low- and high-cortisol response displayed a melanin-based trait to different extents demonstrating a genetic link between regulation of stress and colouration.

field, the amounts of hormones artificially administered to animals are beyond the natural physiological levels or do not mimic temporal variations in hormone levels (e.g. circadian rhythms). With such experiments, we therefore face two problems. First, we can produce artefacts by generating an unnatural situation that disturbs physiological processes that require feedback loops to maintain homeostasis. Therefore, a change in colouration following experimental administration of testosterone may not necessarily reflect naturally occurring processes. For example, in the house sparrow, the change in size of the black bib was positively correlated with circulating testosterone levels, whereas castration did not significantly affect the expression of this plumage trait (Buchanan etal., 2001). Another example is when testosterone has no effect on melanogenesis but is biochemically transformed into another hormone that does have an effect (Hirobe etal., 2010). Second, the effect of experimental manipulation of testosterone levels on melanogenesis may only be indirect. Manipulating testosterone levels can induce modifications in physiology and behaviour, which can in turn modify melanogenesis. It may be difficult to administer exact levels of supplemental testosterone, which usually are 
controlled by social interactions or the environment. Third, melanogenesis may be sensitive to testosterone produced locally in the cells or tissues that produce the ornament, but not to testosterone circulating in the blood.

The following description illustrates how experimental manipulation of hormones can be misinterpreted, in this case for glucocorticoids. We implanted nestling barn owls with pellets releasing the hormone corticosterone, which is implicated in behavioural and physiological responses to environmental stress. Although the administration of corticosterone can lead to a decrease in melanin-based colouration (see also San José \& Fitze, 2013), inter-individual variations in colouration observed in the barn owl are due largely to genes rather than environmental factors (Roulin et al., 2008b). Therefore, in the barn owl covariation between melanin-based colouration and the regulation of corticosterone is not due to corticosterone altering melanogenesis, but rather to genes involved in melanogenesis pleiotropically altering the regulation of corticosterone (Almasi et al., 2010). Nevertheless, our results indicate that corticosterone could mediate the condition-dependence of colour expression in other species.

To demonstrate that variations in a given hormone induced by the environment and/or social interactions alter the expression of melanin-based colouration, a specific experimental design is necessary. One should consider a model system where it is known that the environment affects the expression of melanogenesis. This environmental component should then be manipulated to induce modifications in circulating hormones (e.g. experimentally elevating or reducing the levels of social interaction and control), and the receptors on which this hormone binds to modify melanogenesis should be blocked or over-expressed.

An association between melanin-based colouration and phenotypic traits influenced by hormones can be explained by three mechanisms. First, the hormone may be involved in melanin production, implying that its covariation with colouration may be strongest at the time of melanogenesis. This may be the case for testosterone (Fargallo et al., 2007b), glutathione (Galvan \& Alonso-Alvarez, 2008), melanocortins (Ducrest et al., 2008) and corticosterone (Roulin et al., 2008b); see Solano etal. (2006) for other molecules that can alter melanogenesis. Second, differently coloured individuals may show different hormone profiles because they adopt different reproductive strategies (Emaresi etal., 2014), behave differently (Safran et al., 2008) or even because conspecifics react differently when interacting with them (Gonzalez et al., 2002). In that case, covariation between colouration and hormones may take place mainly at specific times, such as during the reproductive season, at the peak of social interactions or under stressful situations. Finally, genes implicated in melanogenesis may pleiotropically regulate hormones, including testosterone (Ducrest et al., 2008), and hence the covariation between colouration and hormones may occur at any time when these melanogenic genes are expressed. Therefore, regardless of whether hormones influence the expression of melanin-based colouration, this colour trait can be associated with many phenotypic attributes (such as body condition) for which the regulation is hormone-dependent.

\section{MELANIN-BASED GOLOURATION AS AN HONEST SIGNAL OF QUALITY}

An important insight from this review is to propose that a colour trait can signal quality honestly not only because it is costly to produce, maintain or wear but also because there is a genetic link between colouration and body condition due to pleiotropy or linkage disequilibrium (Section IV). How would such a link be maintained under sexual selection? To discuss this, we must first distinguish between two processes of sexual selection. First, assuming that sexual selection is not directional but varies through time and space, or that different categories of individuals have different mating preferences, the benefit of displaying alternative colour patterns and their associated qualities due to pleiotropy could be maintained by selective mechanisms, such as frequencyor density-dependent mate choice, or by local adaptation and context-dependent selection (different morphs are preferred as mates in different habitats) (Roulin \& Bize, 2007). Second, assuming that sexual selection is directional, with all individuals having the same preference for a given morph, genetic variation in the pleiotropic gene would be maintained if the non-preferred morphs can achieve equal fitness through other frequency-dependent processes. For instance, the non-preferred morph may have other advantages under natural selection (Hurtado-Gonzales, Baldassarre \& Uy, 2010) or inter-sexual selection (Baird, Fox \& McCoy, 1997; Ellers \& Boggs, 2002; Kingston, Rosenthal \& Ryan, 2003; Loyau, Jalme \& Sorci, 2005).

Covariation between colouration and body condition can be the outcome of colouration being plastic (i.e. colouration is sensitive to body condition), from body condition being plastic in a colour-specific way (i.e. differently coloured individuals may regulate body condition differently in relation to a number of ecological factors) or a combination of the two. Melanin is endogenously produced, and potentially as a consequence, is usually found to be strongly heritable, with $h^{2}$ ranging from 0.53 to 1.0 in birds (Roulin \& Ducrest, 2013). I therefore propose that melanin-based colouration is a phenotypic marker of genes, particularly those involved in the expression of fitness-related traits, emphasising the potential role of pleiotropy in generating these covariations. A key aspect is therefore not whether the manipulation of nutrients or hormones affects the expression of colouration but rather the extent to which the environment alters colouration. For example, if the environment accounts for a low proportion of the inter-individual variation in colouration, whereas specific genes explain $50 \%$ of the variation in colouration independent of the environment, the covariation between colouration and body mass may be induced by pleiotropic genes involved in melanogenesis rather than by the environment. Quantitative genetic analyses of melanin-based colouration are therefore necessary to evaluate the potential 
effect of genes versus the environment on the covariation between colour and body condition. This could be achieved by experimentally allocating offspring among rearing environments to break down the potential covariation between the quality of the rearing environment and genetic quality. Another approach is to use pedigree-based information (review in Roulin \& Ducrest, 2013).

\section{HANDICAP MODELS APPLIED TO MELANIN-BASED GOLOURATION}

As discussed above, colouration can signal body condition because of variations in the environment, social interactions and genetics. Therefore, differently coloured individuals (and hence genotypes) will not have the same sensitivity to various sources of stress and in turn to natural and sexual selection processes. The specific role of melanin-based colouration in sexual selection processes remains debated. Sexual selection theory commonly assumes that females have a preference for the best males, who signal absolute quality by displaying costly ornaments. These ornaments can signal quality reliably only if producing, maintaining or wearing/displaying them entails significant costs such that only the best males can afford extravagant ornaments or handicaps (Zahavi, 1975, 1977). Based on this idea, research on melanin-based colourful ornaments has focused on the possibility that production of melanin-based colouration is costly and advertises quality honestly (Jawor \& Breitwisch, 2003; Griffith, Parker \& Olson, 2006; McGraw, 2008). However, because melanin pigments are endogenously produced, these costs have been questioned (Badyaev \& Hill, 2000). The present review confirms that producing, maintaining and wearing/displaying melanin-based traits is not universally costly but taxon specific, with the possibility that the production of melanin may be more sensitive to the environment in invertebrates than in vertebrates (Stoehr, 2006; Table 1). Additional studies are required to determine whether costs involved in melanin-based colouration are taxon specific. Although a variety of costs can be invoked to explain why melanin-based colouration is so often associated with body condition (Section IV), the role of pleiotropy has only recently been considered a potent mechanism (Ducrest et al., 2008; Wittkopp \& Beldade, 2009; Reissmann \& Ludwig, 2013). This justifies discussion of the various handicap models (Møller, 1994) of how melanin-based colouration could signal quality honestly to potential mates, keeping in mind that not all individuals may have the same preference for potential mates (i.e. sexual selection may not be directional).

\section{(1) Conditional handicaps or costs of producing melanin-based colouration}

Conditional handicaps refer to traits for which expression depends on the quality of an individual or on its condition (Fig. 1A). Here, the association between colouration and condition is not related to a particular aspect of condition but to general condition. Because a large number of genes are thought to shape inter-individual variation in condition (Rowe \& Houle, 1996), many genes should participate in the production of melanin pigments, for instance, by influencing the expression levels of melanogenic genes. This mechanism is plausible, but it cannot explain all cases of covariation between melanin-based colouration and body condition. In several species, colouration covaries with body condition, even when colouration is strongly heritable and weakly sensitive to variation in the environment and body condition, and even when individuals are experimentally allocated randomly among environments (Roulin \& Ducrest, 2011).

\section{(2) Revealing handicaps or costs of producing melanin-based colouration}

A revealing handicap (Fig. 1B) signals a specific quality, such as parasite resistance (Hamilton \& Zuk, 1982). The expression of the handicap is sensitive for example to parasites, with individuals who do not possess genes conferring parasite resistance having to invest energy and resources in parasite resistance at the expense of ornament production. These genes cannot be considered pleiotropic because they do not belong to the melanogenesis pathway. For melanin-based colouration to signal a body-condition trait such as parasite resistance, the impact of parasitism on colour expression should overwhelm the effect of polymorphism on melanogenic genes, such as MC1R, which can explain most of the inter-individual variation in colouration independent of parasitism (Gangoso et al., 2011). Thus, in cases where a few melanogenic genes account for a large proportion of the variance in colouration, this type of colour trait could not be considered a revealing handicap because the possession or lack of resistant genes will have a relatively weak effect on colour production. It is thus important to measure separately the surface area and intensity of melanin-based patches because these two colour components may be differentially sensitive to genes or to the environment (Poston et al., 2005).

\section{(3) Pure epistatic handicap or costs of wearing a melanin-based colour trait}

An ornament is a 'pure epistatic handicap' (Fig. 1C) if the genes encoding body condition are not the same as those responsible for variation in colouration and if variation in body condition does not affect the expression of colouration (Møller, 1994). A link between body condition and colouration occurs because wearing a given colouration is costly, so that only individuals in prime condition (i.e. possessing so-called 'good genes') can afford the cost of displaying a given colouration. This type of handicap has received little attention because if natural selection on body condition (or fitness) is weak, genetic linkage disequilibrium between the ornament and condition is not expected to occur, whereas in the case where selection is strong, genetic variation in body condition (or fitness) is predicted to disappear quickly. However, these 
A Many genes alter

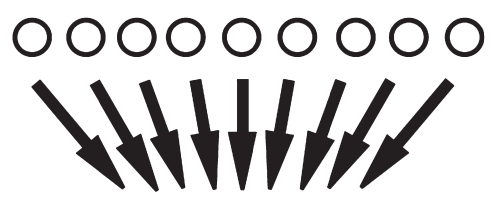

body condition which alter

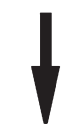

melanin-based colouration

C Different sets of genes alter body condition and coloration

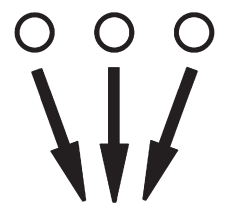

body condition

The display of melanin-based colouration influences body condition
B

One gene alters

O

1

body condition which alters

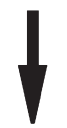

melanin-based colouration

D One gene alters condition AND

melanin-based colouration

Immunity

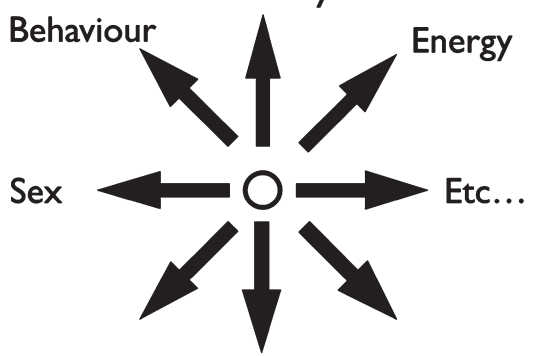

Melanin-based colouration

Fig. 1. Melanin-based colouration can signal quality to potential mates (intersexual selection) or competitors (intrasexual selection) through three major genetic mechanisms. (A) A conditional handicap is when many genes affect body condition (quality or aspects of quality) which in turn affects the expression of an ornament. Thus, the effect of genes on the condition-dependent component of melanin-based colouration is indirect through variation in body condition. (B) A revealing handicap is when one or few genes affect body condition which in turn affects the expression of an ornament. Again, the effect of genes on the condition-dependent component of melanin-based colouration is indirect through variation in body condition. $(\mathrm{C}) \mathrm{A}$ pure epistatic handicap is when genes influencing body condition and an ornament are not the same and when the ornament influences body condition. For instance, the display (e.g. dancing) of an extravagant ornament is energetically costly or time consuming so that melanin-based colouration itself influences body condition. (D) A pleiotropic handicap is when one or few genes affect melanin-based colouration and body condition simultaneously. Thus, body condition does not directly affect melanin-based colouration but the covariation between these two properties occurs because they have gene(s) in common.

theoretical problems vanish under the assumption that selection on body condition and/or colouration is not directional but balancing. Because the expression of melanin-based colouration can be under strong genetic control (Roulin \& Ducrest, 2013), an association between colouration and body condition can indeed arise if the environment is favourable only to individuals displaying a specific colouration. Therefore, for genetic variation in melanin-based colouration to be evolutionarily stable, colouration should confer benefits under specific environmental conditions (i.e. local adaptation), so that the sign of the covariation between colour and body condition can vary depending on whether the environment is favourable to dark or pale individuals. As a consequence, if colouration is used as a mate-choice criterion of individual quality, the preference for a given colouration should be conditional on environmental conditions, with females preferring to mate with males that display the locally adapted colouration (Osawa \& Nishida, 1992; Kingston et al., 2003), a phenomenon that has started to attract the attention of evolutionary biologists (Thibert-Plante \& Gavrilets, 2013).

\section{(4) Pleiotropic handicaps or pleiotropic effects of melanogenic genes}

The three handicap models of sexual selection described above (Fig. 1A-C) assumed that genes encoding body condition indirectly affect the expression of melanin-based colouration (conditional and revealing handicaps) or generate linkage disequilibrium between colouration and body condition through differential costs of wearing alternative colourations (pure epistatic handicap). Because the prevailing theory explaining how ornaments can honestly 
reveal aspects of individual quality does not consider the possibility that one or a few genes pleiotropically regulate the expression of colouration and other behavioural and/or physiological traits (i.e. body condition), I propose a new form of handicap denoted 'pleiotropic handicap' (Fig. 1D). This case is different from the revealing handicap for which the genes encoding a specific quality (such as parasite resistance) do not participate directly in the biochemical cascade leading to colour production but instead allow individuals to reallocate the energy originally intended to be used to resist parasites into the production of colouration. By contrast, pleiotropic genes are implicated in the biochemical cascade leading to the production of colour traits and other phenotypes, such as immune defence. Therefore, different alleles of such pleiotropic genes should be associated with different colouration, behaviour and physiology, implying that alternative colourations are linked to different costs and benefits. For instance, genes encoding a dark (compared to a light) colouration could induce individuals to invest substantial effort in various mechanisms to resist stress factors (e.g. parasites, oxidative stress, rise in glucocorticoid levels), costly activities that are beneficial only if the environment is stressful. Thus, the evolutionary stability of different alleles requires specific mechanisms such as local adaptation and frequency- or density-dependent selection, otherwise variation in colouration and its associated qualities will be rapidly depleted. For instance, a dark colouration may be associated with resistance to stress and a pale colouration with the ability to exploit rich environments efficiently. Thus, when the carrying capacity of an environment is reached, competitive individuals (i.e. dark individuals) have a selective advantage, whereas below the carrying capacity, pale individuals are able to exploit resources more quickly. Therefore, colouration could be associated with alternative life-history strategies, with dark individuals favouring the production of a few high-quality offspring and pale individuals favouring the production of many low-quality offspring (Emaresi etal., 2014). I therefore term this 'pleiotropic handicap' because each colour form is associated with specific costs and benefits that are caused by colouration itself or by genetically correlated traits regulated by pleiotropic genes.

\section{EVOLUTIONARY STABILITY OF GENETIC VARIATION IN MELANIN-BASED COLOURATION}

The hypothesis that genes belonging to the melanogenesis pathway pleiotropically regulate other phenotypic traits (Fig. 1) implies that the degree of melanin-based colouration can be considered a signal of quality, or a marker of other phenotypes if colouration plays no role in sexual selection and social interactions. This raises the question of how variation in pleiotropic genes can be evolutionarily stable. For instance, in the barn owl females displaying larger black spots have a selective advantage (Roulin etal., 2010b) because the size of black spots is associated with many physiological qualities

\section{Alternative strategies / local adaptation}

Trade-off with other physiological processes

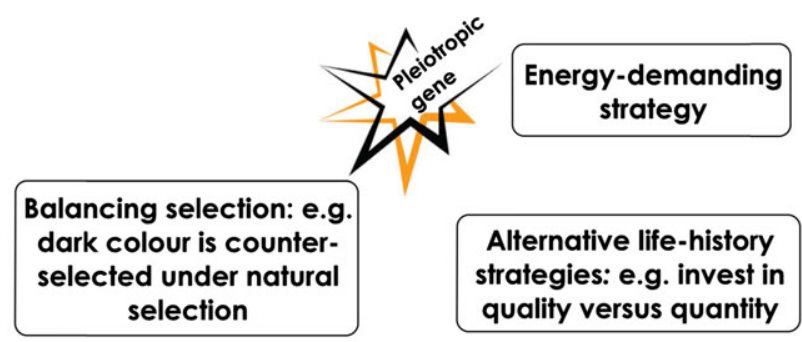

Fig. 2. Evolutionary stability of variation in pleiotropic genes. Alleles at pleiotropic genes can persist in populations if they are associated with colour-specific (life-history) strategies or if these alleles are adapted to different environmental conditions.

which allow individuals to cope with a variety of stressful factors (Roulin \& Ducrest, 2011). This raises the question of how variation in the genes responsible for the size of black feather spots is maintained.

Because the covariation between melanism and quality (or aspects of quality) has a genetic basis, the key question is how alleles can coexist over the long term in a population despite not being selectively neutral. Although the maintenance of genetic diversity should involve frequency- (density-)dependent selection or local adaptation (Maynard-Smith, 1982), the key issue is whether individuals that express pleiotropic genes at a lower level benefit sufficiently to allow these alleles to persist. I suggest five scenarios, which are summarised in Fig. 2.

\section{(1) Trade-offs between physiological processes}

The production of melanin pigments may require genes that positively affect body condition and other genes that negatively affect body condition. For instance, the antioxidant glutathione favours pheomelanogenesis over eumelanogenesis so that the production of eumelanin-based colour traits may be at the expense of resistance to oxidative stress (Galvan \& Alonso-Alvarez, 2008). Therefore, if melanocortins induce eumelanogenesis and other beneficial traits, such as immunity (Ducrest et al., 2008), glutathione levels must be sufficiently low level to allow production of eumelanin. Because resistance to oxidative stress can be achieved through melanocortins or glutathione, producing a deeply or weakly eumelanic body could be considered selectively equivalent alternative strategies. Note that each strategy may be favoured in different environments if the effect of the underlying machinery generating colour variation depends on the environment (Simons et al., 2014).

\section{(2) Energy-demanding strategy}

Melanocortins induce a number of behavioural and physiological functions that can be costly to sustain. Investing 
in a diversity of functions may prove detrimental under some ecological conditions. For instance, maintaining a potent immune system may be costly in the presence of benign parasites (Heeb etal., 1998). Therefore, if the expression of a dark melanic body is due to pleiotropic genes, dark colouration can be considered a costly/high-benefit strategy, and pale colouration a cheap/low-benefit strategy.

\section{(3) Alternative life-history strategies}

Because the pleiotropic effects of melanogenic genes may improve the efficiency with which individuals cope with stressful factors, those individuals may invest in offspring quality rather than offspring number (Emaresi et al., 2014). Thus, variation in the way pleiotropic genes are regulated may be maintained because individuals may differently address life-history trade-offs, such as the trade-off between offspring number and quality (Wolf et al., 2007).

\section{(4) Balancing selection}

If dark colouration is associated with a number of beneficial phenotypes, lighter-coloured individuals may still coexist if they have another advantage, such as if light colouration confers better camouflage.

\section{(5) Sexually antagonistic selection}

Because melanogenic genes can pleiotropically regulate sexual hormones (Ducrest et al., 2008), they may differentially affect males and females. Thus variation in pleiotropic genes might be maintained through sexually antagonistic selection, with males and females being selected in opposite directions (Bonduriansky \& Chenoweth, 2009; Roulin et al., 2010b). As a consequence, one allele of pleiotropic genes could confer advantages to males and another allele to females.

\section{ADAPTIVE FUNGTION OF DIFFERENT FORMS OF COLOUR VARIATION}

Melanin-based colouration can have several functions that can also be species-specific (Meunier et al., 2011). Given the scarcity of experimental studies on the potential adaptive functions of such colour traits and the need to know more about the underlying mechanisms that generate inter-individual variation in colouration, melanin-based colour traits cannot yet be classified into categories of adaptive function. Nevertheless, a number of issues should be considered while studying the function of colour traits.

In species for which the environment is stable over time, traits that play a role in camouflage are likely to be strongly heritable so that individuals can specialise in exploiting a habitat in which they are cryptic. By contrast, in species for which the environment varies over time, colouration may be plastic, as observed in insects, to allow individuals to achieve crypsis (Leimar, 2009; Johansson \& Nilsson-Örtman, 2013).
Such traits are likely to occupy a large part of the body surface that is most visible to predators (e.g. the back in reptiles and the ventral body side in birds). It follows that a correlation between this type of colour trait and body condition may be generated by predator-prey relationships.

Badges of status have usually been considered to be large black surfaces displayed on the breast, as in sparrows, siskins or wasps (Senar \& Camerino, 1998; Tibbetts, 2008; Diep \& Westneat, 2013). However, darker individuals, regardless of whether the colour trait is a badge, are usually more aggressive than paler conspecifics (Ducrest etal., 2008) suggesting that the definition of 'badges of status' may be relaxed and extended to other melanin-based colour traits.

Variations in melanin-based colouration can be either continuous, as in barn swallows (Hirundo rustica), or discrete, as in Eleonora's falcons (Falco eleonorae). These two types of colour traits have usually been considered fundamentally different for two reasons. First, the expression of continuously varying traits is thought to be more sensitive to environmental factors than discrete traits that may be under the control of genes of major phenotypic effects, such as $M C 1 R$ in vertebrates. However, there are species for which variation in colouration is continuous, strongly heritable and weakly sensitive to the environment (e.g. Roulin \& Ducrest, 2013). Second, the mechanisms that may maintain colour variation may be different in continuously varying colour traits versus discrete colour polymorphisms, implying that the adaptive functions of these traits may not be the same. This dichotomy should be relaxed, something that researchers are now more inclined to do (e.g. studies in pied flycatchers showing that continuous variation in the degree of black colouration could be considered a polymorphism; Sirkiä, Virolainen \& Laaksonen, 2010), because a large portion of the continuous variation could be due to two alleles at a gene having major phenotypic effects (e.g. $M C 1 R$ ), whereas continuous variation in colouration within each $M C 1 R$ genotype may be caused by other genes (Roulin \& Ducrest, 2013). A key issue to investigate is whether the genes encoding major phenotypic effects have few pleiotropic effects (such as MC1R) and the genes that explain residual variation in colouration have pleiotropic effects. If this is the case, mechanisms that maintain genetic variation may differ between genes of major and minor phenotypic effects (see also discussion in Roulin \& Ducrest, 2013).

Traits for which variation in colouration is primarily due to pheomelanin versus eumelanin levels should be distinguished. Not only is colouration different (variation in the degree of reddishness versus blackness), but different genes and metabolites are also involved in pheomelanin and eumelanin production, which can have different physiological effects (Ducrest etal., 2008; Galvan \& Alonso-Alvarez, 2008). It should, however, be noted that reddish colourations are based on both pheomelanin and eumelanin pigments (McGraw, Safran \& Wakamatsu, 2005; Fargallo et al., 2007a; Roulin et al., 2008a; Gasparini et al., 2009; Saino et al., 2013b); hence, it might be useful to measure the ratio of pheomelanin to eumelanin (Saino etal., 2013b). The best organisms to study would be those in which some parts of the body 
vary in the degree of reddishness and/or size of reddish patches, while other parts of the body vary in the degree of blackness and/or size of black patches. The barn owl varies from dark pheomelanic to white (pheomelanin-based trait) and from immaculate to heavily marked with black spots (eumelanin-based trait), making it an ideal experimental subject in this regard.

These research agendas will provide useful insights into the evolution, maintenance and adaptive functions of melanin-based colour traits.

\section{GONGLUSIONS}

(1) The evolutionary and proximate mechanisms underlying covariation between melanin-based colouration and body condition are diverse.

(2) Melanin-based colouration can be costly to produce, maintain or wear, as predicted by current theories of sexual selection. Thus, we can predict that a given colour trait (e.g. dark melanic or depigmented colour traits) can signal absolute quality to potential mates. However, inter-individual variation in melanin-based colouration can have a strong genetic component while still covarying with body condition. Many genes participate in melanogenesis, some of which pleiotropically regulate other phenotypes (Ducrest et al., 2008; Wittkopp \& Beldade, 2009; Reissmann \& Ludwig, 2013), potentially explaining why genetically inherited colouration can signal aspects of quality. Other potential mechanisms accounting for covariation between colouration and phenotypic traits are a fluctuating environment and shared biochemical pathways between melanogenesis and body condition (e.g. hormones).

(3) Theoretical models can predict how an ornament can signal quality honestly (Fig. 1). Four major genetic models are described: (i) a conditional handicap, where many genes affect body condition, which in turn affects melanin-based colouration; (ii) a revealing handicap, where one (or a few) gene(s) affect body condition which in turn affects melanin-based colouration; (iii) a pure epistatic handicap where different sets of genes influence body condition and melanin-based colouration; and (iv) a pleiotropic handicap, where one (or a few) gene(s) simultaneously affect melanin-based colouration and other phenotypic traits. Pleiotropy is a handicap because pleiotropic genes induce specific physiological processes that may not be adapted to all environmental conditions (Fig. 2). Therefore, only for the pleiotropic handicap model do the genes that generate the covariation between melanin-based colouration and body condition belong to the melanogenesis pathway.

(4) Pleiotropy is interesting for three reasons. First, given the strong link between colouration and pleiotropic genes, colouration can be considered as an honest genetic marker of quality. Second, the maintenance of genetic variation implies that different alleles at these pleiotropic genes should confer selectively equivalent advantages. Third, the evolution of colouration can proceed through direct selection on colouration and indirect selection on genetically correlated traits.

(5) The study of melanin-based colouration is complex and forces us to be creative to understand the diversity of selective mechanisms that can explain its adaptive value. Pleiotropy might prove a fruitful novel direction.

\section{AGKNOWLEDGEMENTS}

I thank the Swiss National Science Foundation for funding (31003A-120517). I am grateful to two anonymous reviewers, Anne-Lyse Ducrest and Luis San José Garcia who provided very useful comments to improve this manuscript.

\section{REFERENGES}

Adamik, P. \& Vanakova, M. (2011). Feather ornaments are dynamic traits in the great tit Parus major. Ibis 153, 357-362.

Almasi, B., Jenni, L., Jenni-Eiermann, S. \& Roulin, A. (2010). Regulation of stress-response is heritable and functionally linked to melanin-based colouration. Fournal of Evolutionary Biology 23, 987-996.

Andersson, M. (1994). Sexual Selection. Princeton University Press, Princeton.

Armitage, S. A. O. \& Siva-Jothy, M. T. (2005). Immune function responds to selection for cuticular colour in Tenebrio molitor. Heredity 94, 650-656.

Ayala, F. J. \& Campbell, C. A. (1974). Frequency-dependent selection. Annual Review of Ecology and Systematics 5, 115-138.

Badyaev, A. V.\& Hill, G. E. (2000). Evolution of sexual dichromatism: contribution of carotenoid- versus melanin-based colouration. Biological fournal of the Linnean Society 69, 153-172.

Baird, T. A., Fox, S. F. \& McCoy, J. K. (1997). Population differences in the roles of size and coloration in intra- and intersexual selection in the collared lizard, Crotaphytus collaris: influence of habitat and social organization. Behavioral Ecology 8, $506-517$.

Beani, L. \& Turillazzi, S. (1999). Stripes display in hover-wasps (Vespidae: Sternogastrinae): a socially costly status badge. Animal Behaviour 57, 1233-1239.

BELL, G. (2010). Fluctuating selection: the perpetual renewal of adaptation in variable environments. Philosophical Transactions of the Royal Society of London, Series B: Biological Sciences 365, 87-97.

Bize, P., Gasparini, J., Klopfenstein, A., Altwegg, R. \& Roulin, A. (2006). Melanin-based colouration is a non-directionally selected sex-specific signal of offspring development in the Alpine swift. Evolution 60, 2370-2380.

Bond, A. B. (2007). The evolution of colour polymorphism: crypticity searching images, and apostatic selection. Annual Review of Ecology and Systematics 38, 489-514.

Bonduriansky, R. \& Chenoweth, S. F. (2009). Intralocus sexual conflict. Trends in Ecology \& Evolution 24, 280-284.

Bonser, R. H. C. (1995). Melanin and the abrasion resistance of feathers. Condor $\mathbf{9 7}$ $590-591$.

van den Brink, V., Dolivo, V., Falourd, X., Dreiss, A. N. \& Roulin, A. (2012). Melanic colour-dependent anti-predator behavior strategies in barn owl nestlings. Behavioral Ecology 23, 473-480.

Broggi, J., Gamero, A., Hohtola, E., Orell, M. \& Nilson, J.-Å. (2011). Interpopulation variation in contour feather structure is environmentally determined in great tits. PLOS ONE 6, e24942.

Bubenik, G. A. \& Bubenik, A. B. (1985). Seasonal variations in hair pigmentation of white-tailed deer and their relationship to sexual activity and plasma testosterone. Journal of Experimental Zoology 235, 387-395.

Buchanan, K. L., Evans, M. R., Goldsmith, A. R., Bryant, D. M. \& Rowe, L V. (2001). Testosterone influences basal metabolic rate in male house sparrows: a new cost of dominance signalling? Proceedings of the Royal Society of London Series B 268, $1337-1344$.

Burley, N. (1977). Parental investment, mate choice, and mate quality. Proceedings of the National Academy of Sciences of the United States of America 74, 3476-3479.

Caesar, S., Ahnesjö, J. \& Forsman, A. (2007). Testing the role of coadapted genes versus bet-hedging for mating strategies in colour polymorphic pygmy grasshoppers. Biological Journal of the Linnean Society 90, 491-499. 
Caro, T., Stankowich, T., Mesnick, S. L., Costa, D. P. \& Beeman, K. (2012). Pelage colouration in pinnipeds: functional considerations. Behavioral Ecology 23, $765-774$.

Castella, B., Golay, J., Monney, J.-C., Golay, P., Mebert, K. \& Dubey, S. (2013). Melanism, body condition and elevational distribution in the asp viper. Fournal of Zoology 290, 273-280.

Charter, M., Peleg, O., Leshem, Y. \& Roulin, A. (2012). Similar patterns of local barn owl adaptation in the Middle East and Europe with respect to melanic colouration. Biological Fournal of the Linnean Society 106, 447-454.

Clusella-Trullas, S., Terblanche, J. S., Blackburn, T. M. \& Chown, S. L. (2008). Testing the thermal melanism hypothesis: a macrophysiological approach. Functional Ecology 22, 232-238.

Cooke, F., Mirsky, P. J. \& Seiger, M. B. (1972). Colour preference in the lesser snow goose and their possible role in mate selection. Canadian fournal of Zoology $\mathbf{5 0}$ $529-536$.

Cotton, S., Fowler, K. \& Pomiankowski, A. (2004). Do sexual ornaments demonstrate heightened condition-dependent expression as predicted by the handicap hypothesis? Proceedings of the Royal Society of London Series B 271, 771-783.

Culumber, Z. W. \& Rosenthal, G. G. (2013). Mating preferences do not maintain the tailspot polymorphism in the platyfish, Xiphophorus variatus. Behavioral Ecology 24, 1286-1291.

D'Alba, L., Van Hemert, G., Spencer, K. A., Heidinger, B. J., Gill, L., Evans, N. P., Monaghan, P., Handel, C. M. \& Shawkey, M. D. (2014). Melanin-based color of plumage: role of condition and of feather's microstructure. Integrative and Comparative Biology 54, 633-644.

Da Silva, A., Van den Brink, V., Emaresi, G., Luzio, E., Bize, P., Dreiss, A. N. \& Roulin, A. (2013). Melanin-based colour polymorphism signals agressive personality in nest and territory defence in the tawny owl (Strix aluco). Behavioral Ecology and Sociobiology 67, 1041-1052.

Dawson, A., Hinsley, S. A., Ferns, P. N., Bonser, R. H. C. \& Eccleston, L. (2000). Rate of moult affects feather quality: a mechanism linking current reproductive effort to future survival. Proceedings of the Royal Society of London Series B 267, 2093-2098

Delhey, K., Burger, C., Fiedler, W. \& Peters, A. (2010). Seasonal changes in colour: a comparison of structural, melanin- and carotenoid-based plumage colours. PLOS ONE 5, el1582.

DesRochers, D. W., Reed, J. M., Awerman, J., Kluge, J. A., Wilkinson, J., van Griethuijsen, L. I. \& Romero, L. M. (2009). Exogenous and endogenous corticosterone alter feather quality. Comparative Biochemistry and Physiology A: Molecular E̊ Integrative Physiology 152, 46-52.

DieP, S. K. \& WeSTNEAT, D. F. (2013). The integration of function and ontogeny in the evolution of status signal. Behaviour 150, 1015-1044.

Dreiss, A. N. \& Roulin, A. (2010). Age-related change in melanin-based colouration: females that become more female-like and males more male-like with age perform better in barn owls (Tyto alba). Biological Journal of the Linnean Society 101, 689-704.

Dubach, M. (1981). Quantitative analysis of the respiratory system of the house sparrow, budgerigar and violet-eared hummingbird. Respiration Physiology 46, 43-60.

Ducrest, A.-L., Keller, L. \& Roulin, A. (2008). Pleiotropy in the melanocortin system, coloration and behavioural syndromes. Trends in Ecology \& Evolution 23, $502-510$.

Eising, C. M., Müller, W. \& Groothuis, T. G. G. (2006). Avian mothers create different phenotypes by hormone deposition in their eggs. Biology Letters 2, 20-22.

Eldar, A. \& Elowitz, M. B. (2010). Functional roles for noise in genetic circuits. Nature 467, 167-173.

Ellers, J. \& Boggs, C. L. (2002). The evolution fo wing color in Colias butterflies: heritability, sex linkage, and population divergence. Evolution 56, 836-840.

Ellers, J. \& Boggs, C. L. (2003). The evolution of wing colour: male mate choice opposes adaptive wing colour divergence in Colias butterflies. Evolution 57, $1100-1106$.

Emaresi, G., Bize, P., Altwegg, R., Henry, I., van den Brink, V., Gasparini, J. \& Roulin, A. (2014). Melanin-specific life-history strategies. American Naturalist 183 269-280.

Emaresi, G., Ducrest, A.-L., Bize, P., Richter, H., Simon, G. \& Roulin, A. (2013). Pleiotropy in the melanocortin system: expression levels of this system are associated with melanogenesis and pigmentation in the tawny owl (Strix aluco). Molecular Ecology 22, 4915-4930.

Fabricant, S. A., Kemp, D. J., Krajicek, J., Bosakova, Z. \& Herberstein, M. E. (2013). Mechanisms of colour production in a highly variable shield-back stinkbug, Tectocoris diopthalmus (Heteroptera: Scutelleridae), and why it matters. PLoS ONE 8, e64082.

Fargallo, V. R. \& Forstner, M. R. J. (2012). Predation and the maintenance of colour polymorphism in a habitat specialist squamate. PLoS ONE 7, e30316.

Fargallo, J. A., Laaksonen, T., Korpimäki, E. \& Wakamatsu, K. (2007a). A melanin-based trait reflects environmental growth conditions of nestling male Eurasian kestrels. Evolutionary Ecology 21, 157-171.

Fargallo, J. A., Martínez-Padilla, J., Toledano-Díaz, A., Santiago-Moreno, J. \& Dávila, J. A. (2007b). Sex and testosterone effects on growth, immunity and melanin colouration of nestling Eurasian kestrels. Fournal of Animal Ecology 76, 201-209.

Fernandez, A. A. \& Morris, M. R. (2008). Mate choice for more melanin as a mechanism to maintain a functional oncogene. Proceedings of the National Academy of Sciences of the United States of America 105, 13503-13507.

Ferns, P. N. \& Hinsley, S. A. (2004). Immaculate tits: head plumage pattern as an indicator of quality in birds. Animal Behaviour 67, 261-272.

Fitze, P. S. \& Richner, H. (2002). Differential effects of a parasite on ornamental structures based on melanins and carotenoids. Behavioral Ecology 13, 401-407.

FitZPATRICK, S. (1998). Colour schemes for birds: structural coloration and signals of quality in feathers. Annales Zoologici Fennici 35, 67-77.

Folstad, I. \& Karter, A. J. (1992). Parasites, bright males, and the immunocompetence handicap. American Naturalist 139, 603-622.

Fugle, G. N. \& Rothstein, S. I. (1987). Experiments on the control of deceptive signals in white-crowned sparrows. Auk 104, 188-197.

Galvan, I. \& Alonso-Alvarez, C. (2008). An intracellular antioxidant determines the expression of a melanin-based signal in a bird. PLoS ONE 3, e3335.

Gangoso, L., Grande, J. M., Ducrest, A.-L., Figuerola, J., Bortolotti, G., José, A. \& Roulin, A. (2011). Mc1R-dependent melanin-based colour polymorphism is associated with cell-mediated response in the Eleonora's falcon. Fournal of Evolutionary Biology 24, 2055-2063.

Gasparini, J., Bize, P., Piault, R., Kazumasa, W., Blount, J. \& Roulin, A. (2009). Strength and cost of mounting an immune response are associated with a heritable melanin-based colour trait in female tawny owls. Fournal of Animal Ecology 78, 608-616.

GetTy, T. (2006). Sexually selected signals are not similar to sports handicaps. Trends in Ecology \& Evolution 21, 83-88.

Gonzalez, G., Sorci, G., Møller, A. P., Ninni, P., Haussy, C. \& de Lope, F. (1999). Immunocompetence and condition-dependent sexual advertisement in male house sparrows (Passer domesticus). Fournal of Animal Ecology 68, 1225-1234.

Gonzalez, G., Sorci, G., Smith, L. C. \& de Lope, F. (2002). Social control and physiological cost of cheating in status signalling male house sparrows (Passer domesticus). Ethology 108, 289-302.

Grasso, M.J., Savalli, U. M. \& Mumme, R. L. (1996). Status signalling in dark-eyed juncos: perceived status of other birds affects dominance interactions. Condor 98, $636-639$.

Gratten, J., Wilson, A. J., Mcrae, A. F., Beraldi, D., Visscher, P. M., Pemberton, J. M. \& Slate, J. (2008). A localized negative genetic correlation constrains microevolution of coat colour in wild sheep. Science 319, 318-320.

GreEnBerg, N. (2002). Ethological aspects of stress in a model lizard, Anolis carolinensis. Integrative and Comparative Biology 42, 526-540.

Grether, G. F., Kolluru, G. R. \& Nersissian, K. (2004). Individual colour patches as multicomponent signals. Biological Reviews 79, 583-610.

Griffith, S. G., Parker, T. H. \& Olson, V. A. (2006). Melanin-versus carotenoid-based sexual signals: is the difference really so black and red? Animal Behaviour 71, 749-763.

Groothuis, T. \& Meeuwissen, G. (1992). The influence of testosterone on the development and fixation of the form of displays in two age classes of young black-headed gulls. Animal Behaviour 43, 189-208.

Guindre-Parker, S. \& Love, O. P. (2014). Revisiting the condition-dependence of melanin-based plumage. Foumal of Avian Biology 45, 29-33.

Hadfield, J. D. \& Owens, I. P. F. (2006). Strong environmental determination of a carotenoid-based plumage trait is not mediated by carotenoid availability. Fournal of Evolutionary Biology 19, 1104-1114.

Hamilton, W. D. \& Zuk, M. (1982). Heritable true fitness and bright birds: a role for parasites? Science 218, 384-387.

Hanssen, S. A., Folstad, I. \& Erikstad, K. E. (2006). White plumage reflects individual quality in female eiders. Animal Behaviour 71, 337-343.

Hasegawa, M., Arai, E., Watanabe, M. \& Nakamura, M. (2014). Colourful males hold high quality territories but exhibit reduced paternal care in barn swallows. Behaviour 151, 591-612.

Hasley, L. G., Wallace, S. E., Woakes, A. J., Winkler, H. \& Butler, P. J. (2005). Tufted ducks Aythya fuligula do not control buoyancy during diving. Fournal of Avian Biology 36, 261-267.

Heeb, P., Werner, I., Kölliker, M. \& Richner, H. (1998). Benefits of induced host responses against an ectoparasite. Proceedings of the Royal Society of London Series B 265, $51-56$.

HiLl, W. L. (1991). Correlates of male mating success in the ruff Philomachus pugnax, a lekking shorebird. Behavioral Ecology and Sociobiology 29, 367-372.

Hill, G. E. (2011). Condition-dependent traits as signals of the functionality of vital cellular processes. Ecology Letters 14, 625-634.

Hill, G. E. \& Brawner, W. R. (1998). Melanin-based plumage colouration in the house finch is unaffected by coccidial infection. Proceedings of the Royal Society of London B 265, 1105-1109.

Hill, G. E., Montgomerie, R., Inouye, C. Y. \& Dales, J. (1994). Influence of dietary carotenoids on plasma and plumage color in the house finch - intrasexual and intersexual variation. Functional Ecology 8, 343-350. 
Hirobe, T., Kiuchi, M., Wakamatsu, K. \& Ito, S. (2010). Estrogen increases hair pigmentation in female recessive yellow mice. Zoological Science 27, 470-476.

HoI, H. \& GRIGGIO, M. (2008). Dual utility of a melanin-based ornament in bearded tits. Ethology 114, 1094-1100.

Houtman, A. M. \& Falls, J. B. (1994). Negative assortative mating in the white-throated sparrow, Zonotrichia albicollis: the role of mate choice and intra-sexual competition. Animal Behaviour 48, 377-383.

Hughes, K. A., Du, L., Rodd, F. H. \& Reznick, D. N. (1999). Familiarity leads to female mate preference for novel males in the guppy, Poecilia reticulata. Animal Behaviour 58, 907-916.

Hughes, K. A., Houde, A. E., Price, A. C. \& Rodd, F. H. (2013). Mating advantage for rare males in wild guppy populations. Nature 503, 108-111.

Hugie, D. M. \& Lank, D. B. (1997). The resident's dilemma: female choice model for the evolution of alternative mating strategies in lekking male ruffs (Philomachus pugnax). Behavioral Ecology 8, 218-225.

Hurtado-Gonzales, J. L., Baldassarre, D. T. \& Uy, J. A. C. (2010). Interaction between female mating preferences and predation may explain the maintenance of rare males in the pentamorphic fish Poecilia parae. Fournal of Evolutionary Biology 23, 1293-1301.

Iserbyt, A., Bots, J., van Gossum, H. \& Sherratt, T. N. (2013). Negative frequency-dependent selection or alternative reproductive tactics: maintenance of female polymorphism in natural populations. BMC Evolutionary Biology 13, 139

Iwasa, Y. \& Pomiankowski, A. (1991). The evolution of costly mate preferences. 2. The handicap principle. Evolution 45, 1431-1442

Jacob, A., Evanno, G., von Siebenthal, B. A., Grossen, C. \& Wedekind, C. (2010). Effects of different mating scenarios on embryo viability in brown trout. Molecular Ecology 19, 5296-5307.

Jawor, J. M. \& Breitwisch, R. (2003). Melanin ornaments, honesty, and sexual selection. Auk 120, 249-265.

Johansson, F. \& Nilsson-Örtman, V. (2013). Predation and the relative importance of larval colour polymorphisms and colour polyphenism in a damselfly. Evolutionary Ecology 27, 579-591.

Johnstone, R. A. (1995). Sexual selection, honest advertisement and the handicap principle - Reviewing the evidence. Biological Reviews 70, 1-65.

Kim, S.-Y., Fargallo, J. A., Vergara, P. \& Martinez-Padilla, J. (2013). Multivariate heredity of melanin-based colouration, body mass and immunity. Heredity 111, 139-146.

Kingma, S. A., Szentirmai, I., Szekely, T., Bokony, V., Bleeker, M., Liker, A. \& Komdeur, J. (2008). Sexual selection and the function of a melanin-based plumage ornament in polygamous penduline tits Remiz pendulinus. Behavioral Ecology and Sociobiology 62, 1277-1288.

Kingsolver, J. G. \& Diamond, S. E. (2011). Phenotypic selection in natural populations: what limits directional selection? American Naturalist 177, 346-357.

Kingston, J.J., Rosenthal, G. G. \& Ryan, M.J. (2003). The role of sexual selection in maintaining a colour polymorphism in the pygmy swordtail, Xiphophorus pygmaeus. Animal Behaviour 65, 735-743.

Kittilsen, S., Schjolden, J., Beitnes-Johansen, I., Shaw, J. C., Pottinger, T. G., Sorensen, C., Braastad, B. O., Bakken, M. \& Overli, O. (2009). Melanin-based skin spots reflect stress responsiveness in salmonid fish. Hormones and Behavior 56, 292-298.

Kivanova, A., Horakova, D. \& Exnerova, A. (2011). Nest defence intensity in house sparrows Passer domesticus in relation to parental quality and brood value. Acta Ormithologica 46, 47-54.

Kose, M. \& MøLler, A. P. (1999). Sexual selection, feather breakage and parasites: the importance of white spots in the tail of the barn swallow (Hirundo rustica). Behavioral Ecology and Sociobiology 45, 430-436.

Larsen, H. A. S., Austb $\varnothing$, L., Mørkøre, T., Thorsen, J., Hordvik, I., Fischer, U., Jirillo, E., Rimstad, E. \& KoppanG, E. O. (2012). Pigment-producing granulomatous myopathy in Atlantic salmon: a novel inflammatory response. Fish E Shellfish Immunology 33, 277-285.

Leimar, O. (2009). Environmental and genetic cues in the evolution of phenotypic polymorphism. Evolutionary Ecology 23, 125-135.

Less, H., Angelovici, R., Tzin, V. \& Galili, G. (2011). Coordinated gene networks regulating Arabidopsis plant metabolism in response to various stresses and nutritional cues. Plant Cell 23, 1264-1271.

Lin, S. J., Foley, J., Jiang, T. X., Yeh, G. Y., Wu, P., Foley, A., Yen, G. M., Huang, Y. C., Cheng, H. C., Chen, C. F., Reeder, B., Jee, S. H., Widelitz, R. B. \& Chuong, C. M. (2013). Topology of feather melanocyte progenitor niche allows complex pigment patterns to emerge. Science 340, 1442-1445.

Losey, J. E., Uves, A. R., Harmon, J., Ballantyne, F. \& Brown, C. (1997). A polymorphism maintained by opposite patterns of parasitism and predation. Nature 388, 269-272.

Loyau, A., Jalme, M. S. \& Sorci, G. (2005). Intra- and intersexual selection for multiple traits in the peacock (Pavo cristatus). Ethology 111, 810-820.

Malka, S., Hawkins, M. G., Jones, J. H., Pascoe, P. J., Kass, P. H. \& Wisner, E. R. (2009). Effect of body position on respiratory system volumes in anesthetized red-tailed hawks (Buteo jamaicensis) as measured via computed tomography. American fournal of Veterinary Research 70, 1155-1160.
Marie-Orleach, L., Roussel, J. M., Bugeon, J., Tremblay, J., Ombredane, D. \& Evanno, G. (2014). Melanin-based colouration of sneaker male Atlantic salmon is linked to viability and emergence timing of their offspring. Biological fournal of the Linnean Society 111, 126-135.

Martin-Vivaldi, M., Pena, A., Peralta-Sanchez, J. M., Sanchez, L., Ananou, S., Ruiz-Rodriguez, M. \& Soler, J. J. (2010). Antimicrobial chemicals in hoopoe preen secretions are produced by symbiotic bacteria. Proceedings of the Royal Society of London B 277, 125-130.

Maynard-Smith, J. (1982). Evolution and the Theory of Games. Cambridge University Press, Cambridge.

McGraw, K. J. (2007). Dietary mineral content influences the expression of melanin-based ornamental colouration. Behavioral Ecology 18, 137-142.

McGraw, K. J. (2008). An update on the honesty of melanin-based colour signals in birds. Pigment Cell \& Melanoma Research 21, 133-138.

McGraw, K. J. \& Hill, G. E. (2000). Differential effects of endoparasitism on the expression of carotenoid- and melanin-based ornamental colouration. Proceedings of the Royal Society of London Series B 267, 1525-1531.

McGraw, K. J., Mackillop, E. A., Dale, J. \& Hauber, M. E. (2002). Different colours reveal different information: how nutritional stress affects the expression of melanin- and structurally based ornamental plumage. Fournal of Experimental Biology 205, 3747-3755.

McGraw, K. J., Safran, R. J. \& Wakamatsu, K. (2005). How feather colour reflects its melanin content. Functional Ecology 19, 816-821.

McGregor, B. A. (1988). Effects of different nutritional regimens on the productivity of Australian cashmere goats and the partitioning of nutrients between cashmere and hair growth. Australian Fournal of Experimental Agriculture 28, 459-467.

McKinnon, J. S. \& Pierotti, M. E. R. (2010). Colour polymorphism and correlated characters: genetic mechanisms and evolution. Molecular Ecology 19, 5101-5125.

Meunier, J., Figueiredo Pinto, S., Burri, R. \& Roulin, A. (2011). Eumelanin-based colouration and fitness parameters in birds: a meta-analysis. Behavioral Ecology and Sociobiology 65, 559-567.

Mills, L. S., Zimova, M., Oyler, J., Running, S., Abatzoglou, J. T. \& Lukacs, P. M. (2013). Camouflage mismatch in seasonal coat colour due to decreased snow duration. Proceedings of the National Academy of Sciences of the United States of America 110 $7360-7365$

MøLler, A. P. (1987). Social control of deception among status signalling house sparrows Passer domesticus. Behavioral Ecology and Sociobiology 20, 307-311.

MøLler, A. P. (1994). Sexual Selection and the Barn Swallow. Oxford University Press, Oxford

Moreno-RuedA, G. (2011). House sparrows Passer domesticus with larger uropygial glands show reduced feather wear. Ibis 153, 195-198.

Moyaho, A., Guevara-Fiore, P., Beristain-Castillo, E. \& Garcia, C. M. (2010). Females of a viviparous fish (Skiffia multipunctata) reject males with black colouration. Fournal of Ethology 28, 165-170.

Musolin, D. L., Tougou, D. \& Fujisaki, K. (2010). Too hot to handle? Phenological and life-history responses to simulated climate change of the southern green stink bug Nezara viridula (Heteroptera: Pentatomidae). Global Change Biology 16, 73-87.

Nakagawa, S., Lee, J. W., Woodward, B. K., Hatchwell, B. J. \& Burke, T. (2008). Differential selection according to the degree of cheating in a status signal. Biology Letters 4, 667-669.

Nakagawa, S., Ockendon, N., Gillespie, D. O. S., Hatchwell, B. J. \& Burke, T. (2007). Assessing the function of house sparrows' bib size using a flexible meta-analysis method. Behavioral Ecology 18, 831-840.

Olendorf, R., Rodd, F. H., Punzalan, D., Houde, A. E., Hurt, G., Reznick, D. N. \& Hughes, K. A. (2006). Frequency-dependent survival in natural guppy populations. Nature 441, 633-636.

Olsen, B. J., Greenberg, R., Liu, I. A., Felch, J. M. \& Walters, J. R. (2010). Interactions between sexual and natural selection on the evolution of a plumage badge. Evolutionary Ecology 24, 731-748.

Osawa, N. \& Nishida, T. (1992). Seasonal variation in elytral colour polymorphism in Harmonia asyridis (the ladybird beetle): the role of non-random mating. Heredity 69 297-307.

Pap, P. L., Vagasi, C. I., Osvath, G., Muresan, C. \& Barta, Z. (2010). Seasonality in the uropygial gland size and feather mite abundance in house sparrows Passer domesticus: natural covariation and an experiment. Fournal of Avian Biology 41 , $653-661$.

Piault, R., van den Brink, V. \& Roulin, A. (2012). Condition-dependent expression of melanin-based colouration in the Eurasian kestrel. Naturwissenschaften 99, 391-396.

Piault, R., Gasparini, J., Bize, P., Jenni-Eiermann, S. \& Roulin, A. (2009). Pheomelanin-based colouration and the ability to cope with variation in food supply and parasitism. American Naturalist 174, 548-556.

Piault, R., Gasparini, J., Bize, P., Paulet, M., McGraw, K. \& Roulin, A. (2008). Experimental support for the make-up hypothesis in nestling tawny owls Strix aluco). Behavioral Ecology 19, 847-853.

Piersma, T., Dekker, M. \& Sinninghe Damsté, J. S. (1999). An avian equivalent of make-up? Ecology Letters 2, 201-203. 
Poston, J. P., Hasselquist, D., Stewart, I. R. K. \& Westneat, D. F. (2005). Dietary amino acids influence plumage traits and immune responses of male house sparrows, Passer domesticus, but not as expected. Animal Behaviour 70, $1171-1181$.

Pryke, S. R. (2010). Sex chromosome linkage of mate preference and colour signal maintains assortative mating between interbreeding finch morphs. Evolution 64, $1301-1310$.

Quesada, J. \& Senar, J. C. (2007). The role of melanin- and carotenoid-based plumage coloration in nest defence in the great tit. Ethology 113, 640-647.

Ramniwas, S., Kajla, B., Dev, K. \& Parkash, R. (2013). Direct and correlated responses to laboratory selection for body melanisation in Drosophila melanogaster: support for the melanisation-desiccation resistance hypothesis. Fournal of Experimental Biology 216, 1244-1254.

Reissmann, M. \& Ludwig, A. (2013). Pleiotropic effects of coat colour-associated mutations in humans, mice and other mammals. Seminars in Cell \& Developmental Biology 24, 576-586.

Remes, V. \& Matysioková, B. (2013). More ornamented females produce higher-quality offspring in a socially monogamous bird: an experimental study in the great tit (Parus major). Frontiers in Zoology 10, 14.

Reneerkens, J., Versteegh, M. A., Schneider, A. M., Piersma, T. \& Burtt, E. H. (2008). Seasonally changing preen-wax composition: red knots' (Calidris canutus) flexible defense against feather-degrading bacteria? Auk 125, 285-290.

Rodgers, G. M., Gladman, N. W., Corless, H. F. \& Morrell, L. J. (2013). Costs of colour change in fish: food intake and behavioural decisions. Fournal of Experimental Biology 216, 2760-2767.

RoHWER, S. (1977). Status signaling in Harris sparrows: some experiments in deception. Behaviour 61, 107-129.

Ros, A. F. H. (1999). Effects of testosterone on growth, plumage pigmentation, and mortality in black-headed gull chicks. Ibis 141, 451-459.

Roulin, A. (1999). Nonrandom pairing by male barn owls Tyto alba with respect to a female plumage trait. Behavioral Ecology 10, 688-695.

Roulin, A. (2004). The evolution, maintenance and adaptive function of genetic colour polymorphism in birds. Biological Revieres 79, 815-848.

Roulın, A. (2006). Linkage disequilibrium between a melanin-based colour polymorphism and tail length in the barn owl. Biological Fournal of the Limnean Society 88, $475-488$

Roulin, A. (2009). Covariation between eumelanic pigmentation and body mass only under specific conditions. Natureissenschaften 96, 375-382.

Roulin, A. (2014). Melanin-based colour polymorphism responding to climate change. Global Change Biology 20, 3344-3350.

Roulin, A., Almasi, B. \& Jenni, L. (2010a). Temporal variation in glucocorticoid levels during the resting phase is associated in opposite way with maternal and paternal melanic colouration. Fournal of Evolutionary Biology 23, 2046-2053.

Roulin, A., Altwegg, R., Jensen, H., Steinsland, I. \& Schaub, M. (2010b). Sex-dependent selection on an autosomal melanic female ornament promotes the evolution of sex ratio bias. Ecology Letters 13, 616-626.

Roulin, A., Almasi, B., Rossi-Pedruzzi, A., Ducrest, A.-L., Wakamatsu, K., Miksik, I., Blount, J. D., Jenni-Eiermann, S. \& Jenni, L. (2008a). Corticosterone mediates the condition-dependent component of melanin-based colouration. Animal Behaviour 75, 1351-1358.

Roulin, A., Gasparini, J., Bize, P., Ritschard, M. \& Richner, H. (2008b). Melanin-based colourations signal strategies to cope with poor and rich environments. Behavioral Ecology and Sociobiology 62, 507-519.

Roulin, A. \& AltwegG, R. (2007). Breeding rate is associated with pheomelanism in male and with eumelanism in female barn owls. Behavioral Ecology 18, 563-570.

Roulin, A. \& BizE, P. (2007). Sexual selection in genetic colour-polymorphic species: a review of experimental studies and perspectives. Fournal of Ethology 25, 99-105.

Roulin, A., Bize, P., Ravussin, P.-A. \& Broch, L. (2004). Genetic and environmental effects on the covariation between colour polymorphism and a life history trait. Evolutionary Ecology Research 6, 1253-1260.

Roulin, A. \& Ducrest, A.-L. (2011). Association between melanism, physiology and behaviour: a role for the melanocortin system. European Fournal of Pharmacology 660, $226-233$.

Roulin, A. \& Ducrest, A.-L. (2013). Genetics of colouration in birds. Seminars in Cell and Developmental Biology 24, 594-608.

Roulin, A., Ducrest, A.-L., Balloux, F., Dijkstra, C. \& Riols, C. (2003). A female melanin-ornament signals offspring fluctuating asymmetry in the barn owl. Proceedings of the Royal Society of London B 270, 167-171.

Roulin, A., Emaresi, G., Bize, P., Gasparini, J., Piault, R. \& Ducrest, A.-L. (2011). Pale and dark reddish melanic tawny owls differentially regulate the level of blood circulating POMC prohormone in relation to environmental conditions. Oecologia 166, 913-921.

Roulin, A., Jungi, T. W., Pfister, H. \& Dijkstra, C. (2000). Female barn owls (Tyto alba) advertise good genes. Proceedings of the Royal Society of London B 267, 937-941.

Roulin, A., Richner, H. \& Ducrest, A.-L. (1998). Genetic, environmental, and condition-dependent effects on female and male ornamentation in the barn owl Tyto alba. Evolution 52, 1451-1460.
Roulin, A., Riols, C., Dijkstra, C. \& Ducrest, A.-L. (2001a). Female- and male-specific signals of quality in the barn owl. Journal of Evolutionary Biology 14, 255-267.

Roulin, A., Riols, G., Dijkstra, C. \& Ducrest, A.-L. (2001b). Female plumage spottiness and parasite resistance in the barn owl (Tyto alba). Behavioral Ecology 12, $103-110$.

Rowe, J. W., Clark, D. L., Shaw, D. M. \& Wittle, L. W. (2013). Histological basis of substrate colour-induced melanisation and reversal of melanisation in painted turtles (Chrysemys picta marginata). Chelonian Conservation and Biology 12, 246-251.

Rowe, L. \& Houle, D. (1996). The lek paradox and the capture of genetic variance by condition dependent traits. Proceedings of the Royal Society of London Series B 263, $1415-1421$.

Ruell, E. W., Handelsman, C. A., Hawkins, C. L., Sofaer, H. R., Ghalambor, C. K. \& ANGELONI, L. (2013). Fear, food and sexual ornamentation: plasticity of colour development in Trinidadian guppies. Proceedings of the Royal Society of London B 280, 20122019.

Ruiz-De-Castaneda, R., Burtt, E. H., Gonzalez-Braojos, S. \& Moreno, J. (2012). Bacterial degradability of an intrafeather unmelanized ornament: a role of feather-degrading bacteria in sexual selection? Biological Fournal of the Limnean Society $105,409-419$.

Safran, R. J., Adelman, J. S., McGraw, K. J. \& Hau, M. (2008). Sexual signal exaggeration affects physiological state in male barn swallows. Current Biology 18 , $\mathrm{R} 461-\mathrm{R} 462$.

Safran, R. J., Neuman, C. R., McGraw, K. J. \& Lovette, I. J. (2005). Dynamic paternity allocation as a function of male plumage colour in barn swallows. Science 309, 2210-2212.

Saikawa, Y., Hashimoto, K., Nakata, M., Yoshihara, M., Nagai, K., Ida, M. \& Komiya, T. (2004). The red sweat of the hippopotamus. Nature 429, 363.

Saino, N., Romano, M., Caprioli, M., Lardelli, R., Micheloni, P., Scandolara, C., Rubolini, D. \& Fasola, M. (2013a). Molt, feather growth rate and body condition of male and female barn swallow. Fournal of Ornithology $\mathbf{1 5 4}$, $537-547$.

Saino, N., Romano, M., Rubolini, D., Teplitski, C., Ambrosini, R., Caprioli, M., Canova, L. \& Wakamatsu, K. (2013b). Sexual dimorphism in melanin pigmentation, feather colouration and its heritability in the barn swallow (Hirundo rustica). PLoS ONE 8, e58024.

SAN José, L. M. \& Fitze, P. S. (2013). Corticosterone regulates multiple colour traits in Lacerta (Zootoca) vivipara males. Fournal of Evolutionary Biology 26, 2681-2690.

Santos, E. S. A., Scheck, D. \& Nakagawa, S. (2011). Dominance and plumage traits: meta-analysis and metaregression analysis. Animal Behaviour 82, 3-19.

von Schantz, T., Bensch, S., Grahn, M., Hasselquist, D. \& Wittzell, H. (1999). Good genes, oxidative stress and condition-dependent signals. Proceedings of the Royal Society of London B 266, 1-12.

Senar, J. C. \& Camerino, M. (1998). Status signalling and the ability to recognize dominants: an experiment with siskins (Carduelis spinus). Proceedings of the Royal Society of London. Series B 165, 1515-1520.

SERRA, L. (2001). Duration of primary moult affects primary quality in grey plovers Pluvialis squatarola. Fournal of Avian Biology 32, 377-380.

Siefferman, L. \& Hill, G. E. (2003). Structural and melanin coloration indicate parental effort and reproductive success in male eastern bluebirds. Behavioral Ecology 14, 855-861.

Simons, M. J. P., Briga, M., Leenknegt, B. \& Verhulst, S. (2014). Context-dependent effects of carotenoid supplementation on reproduction in zebra finches. Behavioral Ecology 25, 945-950.

Sinervo, B., Bleay, C. \& Adamopoulou, C. (2001). Social causes of correlational selection and the resolution of a heritable throat colour polymorphism in a lizard. Evolution 55, 2040-2052.

Sirkiä, P. M., Virolainen, M. \& LaAksonen, T. (2010). Melanin colouration has temperature-dependent effects on breeding performance that may maintain phenotypic variation in a passerine bird. Fournal of Evolutionary Biology 23, 2385-2396.

Solano, F., Briganti, S., Picardo, M. \& Ghanem, G. (2006). Hypopigmenting agents: an updated review on biological, chemical and clinical aspects. Pigment Cell \& Melanoma Research 19, 550-571.

STEPHENSON, R. (1993). The contributions of body tissues, respiratory system, and plumage to buoyancy in waterfowl. Canadian Joumal of Zoology 71, 1521-1529.

SteWART, I. R. K. \& WeSTNEAT, D. F. (2010). Dietary calcium negatively affects the size of a status signal in juvenile male house sparrows (Passer domesticus). Auk 127, $549-557$.

Stewart, I. R. K. \& Westneat, D. F. (2013). Dietary calcium, but not a glutathione inhibitor, affects bib size in juvenile male house sparrows. Condor 115, 921-930.

Stoenr, A. M. (2006). Costly melanin ornaments: the importance of taxon? Functional Ecology 20, 276-281.

Stoenr, A. M. (2010). Response of disparate phenotypically-plastic, melanin-based traits to common cues: limits to the benefits of adaptive plasticity? Evolutionary Ecology 24, 287-298.

Surmacki, A., Ozarowska-Nowicka, A. \& Rosin, Z. M. (2013). Colour polymorphism in a land snail Cepaea nemoralis (Pulmonata: Helicidae) as viewed by potential avian predators. Naturwissenschaften 100, 533-540. 
Svensson, E. I., Аввотt, J. \& Hardling, R. (2005). Female polymorphism, frequency dependence, and rapid evolutionary dynamics in natural populations. American Naturalist 165, 567-576.

Svensson, E. I., Eroukhmanoff, F., Karlsson, K., Runemark, A. \& Brodin, A. (2010). A role for learning in population divergence of mate preferences. Evolution 64, 3101-3113.

TAKAHASHI, Y. \& KAWATA, M. (2013). Alternative trait combinations and secondary resource partitioning in sexually selected colour polymorphism. Ecology and Evolution 3, 2038-2046.

Talloen, W., van Dyck, H. \& Lens, L. (2004). The cost of melanisation: butterfly wing colouration under environmental stress. Evolution 58, 360-366.

Tarafder, A. K., Bolasco, G., Correia, M. S., Pereira, J. C., Iannone, L., Hume, A. N., Kirkpatrick, N., Picardo, M., Torrisi, M. R., Rodrigues, I. P., Ramalho, J. S., Futter, C. E., Barral, D. C. \& Seabra, M. C. (2014). Rab1 lb mediates melanin transfer between donor melanocytes and acceptor keratinocytes via coupled exo/endocytosis. Fournal of Investigative Dermatology 134, 1056-1066.

Thibert-Plante, X. \& Gavrilets, S. (2013). Evolution of mate choice and the so-called magic traits in ecological speciation. Ecology Letters 16, 1004-1013.

Tibbetts, E. A. (2008). Resource value and the context dependence of receiver behaviour. Proceedings of the Royal Society of London B 275, 2201-2206.

Tiвbetts, E. A. (2010). The condition dependence and heritability of signalling and nonsignaling colour traits in paper wasps. American Naturalist 175, 495-503.

Tibbetts, E. A. \& Dale, J. (2004). A socially enforced signal of quality in a paper wasp. Nature 432, 218-222.

VAGasi, C. I., PAP, P. L. \& BARTA, Z. (2010). Haste makes waste: accelerated molt adversely affects the expression of melanin-based and depigmented plumage ornaments in house sparrows. PLoS ONE 5, e14215.
Vercken, E., Clobert, J. \& Sinervo, B. (2010). Frequency-dependent reproductive success in female common lizards: a real-life hawk-dove-bully game? Oecologia 162 , $49-58$.

WALKER, W. P. \& GUNN, T. M. (2010). Shades of meaning: the pigment-type switching system as a tool for discovery. Pigment Cell \& Melanoma Research 23, 485-495.

WANG, Z. \& ZHANG, J. (2011). Impact of gene expression noise on organismal fitness and the efficacy of natural selection. Proceedings of the National Academy of Sciences of the United States of America 108, E67-E76.

Wedekind, G., Jacob, A., Evanno, G., Nussle, S. \& Muller, R. (2008). Viability of brown trout embryos positively linked to melanin-based but negatively to carotenoid-based colours of their fathers. Proceedings of the Royal Society of London. Series B 275, 1737-1744.

Wiernasz, D. C. (1995). Male choice on the basis of female melanin pattern in Pieris butterflies. Animal Behaviour 49, 45-51.

Wittkopp, P. J. \& Beldade, P. (2009). Development and evolution of insect pigmentation: genetic mechanisms and the potential consequences of pleiotropy. Seminars in Cell \& Developmental Biology 20,65-71.

Wolf, M., van Doorn, G. S., Leimar, O. \& Weissing, F. J. (2007). Life-history trade-offs favour the evolution of animal personalities. Nature 447, 581-584.

Yu, S., Rogers, Q. R. \& Morris, J. G. (2001). Effect of low levels of dietary tyrosine on the hair colour of cats. Fournal of Small Animal Practice 42, 176-180.

Zahavi, A. (1975). Mate selection - a selection for a handicap. Fournal of Theoretical Biology 53, 205-214

ZAHAVI, A. (1977). The cost of honesty (further remarks on the handicap principle). Journal of Theoretical Biology 67, 603-605.

(Received 16 April 2014; revised 30 November 2014; accepted 11 December 2014; published online 28 January 2015) 